
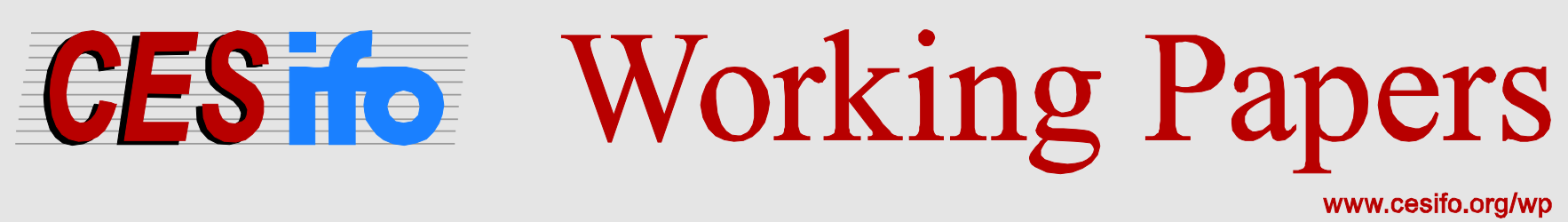

\title{
Technology Transfers for Climate Change
}

\author{
May Elsayyad \\ Florian Morath
}

\section{CESIFO WORKING PAPER NO. 4521 \\ CATEgORY 10: ENERGY AND ClimATE ECONOMICS \\ DECEMBER 2013}

An electronic version of the paper may be downloaded

- from the SSRN website:

WwW.SSRN.com

- from the RePEc website:

- from the CESifo website:

www.RePEc.org

www.CESifo-group.org/wp

\section{CESifo}




\title{
Technology Transfers for Climate Change
}

\begin{abstract}
This paper considers investments in cost-reducing technology in the context of contributions to climate protection. Contributions to mitigating climate change are analyzed in a two-period model where later contributions can be based on better information, but delaying the contribution to the public good is costly because of irreversible damages. We show that, when all countries have access to the new technology, countries have an incentive to invest in technology because this can lead to an earlier contribution of other countries and therefore reduce a country's burden of contributing to the public good. Our results provide a rationale for the support of technology sharing initiatives.
\end{abstract}

JEL-Code: H410, Q520, D620, D830, F530.

Keywords: private provision of public goods, environmental public goods, technology sharing, uncertainty, irreversibility.

May Elsayyad

Max Planck Institute for Tax Law and

Public Finance

Marstallplatz 1

Germany - 80539 Munich

may.elsayyad@tax.mpg.de
Florian Morath

Max Planck Institute for Tax Law and

Public Finance

Marstallplatz 1

Germany - 80539 Munich

florian.morath@tax.mpg.de

September 10, 2013

We thank Kai Konrad, Johannes Münster, Salmai Qari, Monika Schnitzer, Jan-Peter Siedlarek, Marcel Thum, participants of the ESI Workshop in Munich, the SFB-TR-15 conference in Caputh 2012, the APET Conference in Lisbon 2013, the IIPF Congress 2013, and seminar participants at LMU Munich and University of Augsburg for helpful comments and suggestions. 


\section{Introduction}

Getting countries to commit to new post-Kyoto binding $\mathrm{CO}_{2}$ emission reduction targets has hitherto remained an elusive goal. A continued success on an international scale, however, has been the support of renewable technology initiatives. For example, the Cancún Summit in 2011 declared the start of a $\$ 1$ billion new initiative and fund for the exchange of climate change technology. Technology transfer mechanisms have always been a dimension of climate change agreements. Article 4.5 of the United Nations Framework Convention on Climate Change states that countries "shall take all practicable steps to promote, facilitate and finance, as appropriate, the transfer of, or access to, environmentally sound technologies and know-how to other Parties". ${ }^{1}$ In fact, recent studies tracking the development of clean technologies show their steady and persistent rise. ${ }^{2}$

This development is not surprising, given the strong national policies in support of renewable technologies which are being implemented, most notably, by the US and the EU. ${ }^{3}$ However, this support is often controversially debated. Investments in technology can be profitable if they are perceived as investments in new markets. But, in the public good framework of environmental protection, a particularly persistent argument has been that unilateral investments in technology hurt the investing country as other countries can reduce their effort on climate protection in return. ${ }^{4}$ Given the strong international support for technology sharing initiatives, this paper provides an argument in favor of sharing costreducing technologies. A country may provide a new technology, because it can induce other countries not to delay their efforts but instead to contribute to climate protection today.

To develop this rationale, three distinctive features, which influence the decision of contributing to climate protection, are taken into consideration. First, efforts to mitigate global warming are, to a large extent, private contributions to a global public good. As such, the strategic interaction between countries causes strong incentives to delay one's own contribution since, in reaction to the high effort of one country, other countries can reduce their effort on climate protection. Second, international coordination is hampered by the fact that there is uncertainty with regard to the (country-specific) need for climate protection. The uncertainty connected with climate protection stems from the fact that the costs and benefits of environmental damage and its reduction remain largely uncertain. Particularly difficult is the assessment of the impact of climate change, which is highly reliant on differ-

\footnotetext{
${ }^{1}$ Chapter 16 of the Stern Review (2007) identified technology-based schemes as an indispensable strategy to tackle climate change.

${ }^{2}$ See, for instance, UNEP (2011).

${ }^{3}$ See Moselle et al. (2010) for an overview.

${ }^{4}$ For the effects of unilateral actions in a public goods framework see Hoel (1991), Buchholz and Konrad (1994, 1995), Buchholz et al. (2005), and Beccherle and Tirole (2011).
} 
ent projections of the impact of $\mathrm{CO}_{2}$ concentrations on temperatures. ${ }^{5}$ Consequently, such strong uncertainties should push policy-makers towards a later contribution to climate protection, i.e., after the resolution of the uncertainty. Third, greenhouse gas emissions have irreversible consequences and cause damages that may possibly be mitigated only at a very high cost. Therefore, delaying the fight against global warming may prove to be expensive. For example, the accumulation of $\mathrm{CO}_{2}$ emissions in the atmosphere is difficult to reduce, and the damage to the ecosystems from an increase in global temperatures, from acidified lakes and streams, or from the clear-cutting of forests can be permanent. ${ }^{6}$

Our contribution is twofold. First, we extend the standard model of private provision of a public good to a framework that incorporates the important trade-off that countries face when deciding on climate policies: uncertainty versus irreversibility of damages. Our model builds on the classic concept of irreversible investments and the option value of information; however, we consider investments that exhibit a positive externality and therefore affect other players' benefit from investing. ${ }^{7}$ We derive the equilibrium contributions to climate protection and identify the main mechanisms driving the timing of the countries' contribution decisions. In a two-country model, we show that, for low degrees of irreversibility, both countries would like to wait until the resolution of the uncertainty, while for high degrees of irreversibility the opposite is the case. For intermediate ranges of irreversibility, an alternating equilibrium emerges where one country contributes early and the other country might contribute in a later period of the game; a result strongly in line with empirical observations.

Second, building on these results, we analyze how an investment in cost-reducing technology by one country alters both countries' timing decisions of the contributions to climate protection. We consider an investment in technology in the context of technology sharing where both countries have access to the cost-reducing technology. Here, we identify two scenarios where, by a targeted use of cost-reducing technology, one country can induce the other country to increase its current contribution and in this way reduce its own burden of contributing. This free-riding incentive for investments in technology is in sharp contrast to the usual argument that unilateral investments only increase the own burden of contributing.

Our model is related to the literature on the timing of environmental policy adoption. Mainly developed by Arrow and Fisher (1974) and Henry (1974) for the case of irreversible investments, this literature analyzes the trade-off between uncertainty and irreversibility in

\footnotetext{
${ }^{5}$ See Allen et al. (2009) for a summary on $\mathrm{CO}_{2}$ impact projections and their variability.

${ }^{6}$ The 2007 IPCC report on climate change clearly outlines the long-term cost of a "business-as-usual" $\mathrm{CO}_{2}$ emissions path (see Chapter 3 of the IPCC Synthesis Report). For an overview of different aspects of climate protection policies see, for instance, Aldy, Orszag, and Stiglitz (2001).

${ }^{7}$ The results of a standard one-shot public goods game and a model of irreversible investments are obtained as special cases of our model.
} 
a one-player setting and shows that there is an option value to waiting until the resolution of the uncertainty. ${ }^{8}$ Our paper takes up the timing issue of policy adoption and introduces the notions of irreversibility and uncertainty in a standard two-player model where investments are contributions to a public good. This allows us to isolate the effects of uncertainty and irreversibility in the strategic context of contribution considerations. ${ }^{9}$

Methodologically, our study is related to the standard literature on private provision of a public good in a static framework. ${ }^{10}$ In the simplest dynamic two-period framework, our model reinforces the free-riding incentives, as countries can also free-ride on the other players' future contributions, similar to the results of Fershtman and Nitzan (1991) and Admati and Perry (1991) in the context of dynamic contributions to a public good. ${ }^{11}$ Lockwood and Thomas (2002) use the notion of irreversibility in the context of contributions to a public good where, in their model, irreversibility refers to the fact that investments in previous periods cannot be taken back, a feature which is also present in our model. Gradstein (1992) introduces incomplete information into a dynamic two-period model of contributions to a public good and shows that there is inefficient delay of individual contributions.

Bramoullé and Treich (2009) examine a framework with risk averse countries where the effect of pollution emissions is uncertain. In their model, uncertainty leads to higher climate protection efforts, while in our case there is an informational advantage of delaying contributions, which causes current contributions to be lower. In a related study, Boucher and Bramoullé (2010) analyze international cooperation when climate protection benefits are uncertain. ${ }^{12}$ To our knowledge, our study next to Morath (2010) is the first to simultaneously analyze the effects of uncertainty and irreversibility in a context of private contributions to a public good. ${ }^{13}$

Focusing on the interaction between technology and contributions to climate protection, Buchholz and Konrad (1994, 1995) and Buchholz et al. (2005) show that the public good nature of environmental protection might induce countries to be "less green" in order to

\footnotetext{
${ }^{8}$ See also Conrad (1980), Epstein (1980), McDonald and Siegel (1986), Pindyck (1991), Kolstad (1996), Ulph and Ulph (1997), Fisher (2000), Gollier et al. (2000), and Pindyck (2002).

${ }^{9}$ Issues of timing have continued to play a role in the environmental literature with the recent struggles of international coordination in the post-Kyoto era. See Schmidt and Strausz (2011) and Beccherle and Tirole (2011) who analyze the impacts of delayed negotiations.

${ }^{10}$ See the seminal work by Bergstrom et al. (1986) and Cornes and Sandler (1985). Also see Varian (1994) on sequential contributions to a public good.

${ }^{11}$ Compare also Marx and Matthews (2000), Compte and Jehiel (2003), and Kessing (2007).

${ }^{12}$ For aspects of the formation of international environmental treaties under uncertainty see also Na and Shin (1998) and, more recently, Kolstad and Ulph (2008) and Glazer and Proost (2012); see also the literature review in Barrett $(2003,2007)$.

${ }^{13}$ Morath (2010) analyzes countries' incentives to acquire information about the cost of climate change and shows that there can be a strategic advantage of remaining uninformed.
} 
strengthen their bargaining position in the environmental policy coordination game. ${ }^{14}$ This argument has been further generalized by Beccherle and Tirole (2011) and still holds true when introducing uncertainty or dynamics. ${ }^{15}$ This robust result, however, stands in strong contrast to the steady rise of investments in renewable energy. Our model considers investments in technology in the context of technology transfer mechanisms; here, we identify scenarios where a cost-reducing investment, which is shared between both countries, generates an outcome where investments in green technology can actually reduce a country's burden of contributing to the public good. ${ }^{16}$ Our model abstracts from bargaining over a cooperative outcome and highlights the public goods nature of mitigation policies. By affecting the time pattern of contributions, technology sharing can, in a non-cooperative approach, lead to a rise in current contributions to climate protection.

The paper is structured as follows: Section 2 introduces the model framework, and Section 3 solves for the equilibrium contributions. Section 4 isolates the effects of uncertainty, irreversibility, and free-riding on the timing of the contribution. Section 5 analyzes the impact of the technology sharing of a cost-reducing investment on the timing of the contributions, and Section 6 concludes. All proofs are in the appendix.

\section{Model framework}

We consider a framework with two countries $A$ and $B$ and two periods $t$ and $t+1$. In each period, countries simultaneously choose a contribution to a public good where $x_{\tau}^{i} \in \mathbb{R}_{+}$ denotes country $i$ 's contribution in period $\tau, i \in\{A, B\}$ and $\tau \in\{t, t+1\}$. The marginal contribution costs in the two periods are assumed to be constant and identical for both countries and are denoted by $c_{t}(\kappa)>0$ and $c_{t+1}(\kappa)>0 ; \kappa$ refers to the technology available to the countries, and $c_{t}$ and $c_{t+1}$ are assumed to be continuous and differentiable in $\kappa$ (as explained below).

Individual contributions in the two periods sum up to the total amount contributed to the public good. ${ }^{17}$ Hence, country $i$ 's payoff is equal to

$$
\pi_{i}=\theta^{i} f\left(\sum_{\tau=t, t+1} \sum_{i=A, B} x_{\tau}^{i}\right)-c_{t} x_{t}^{i}-c_{t+1} x_{t+1}^{i}, i \in\{A, B\} .
$$

\footnotetext{
${ }^{14}$ See also the results of Shah (2010) in the context of negotiations of emission caps.

${ }^{15}$ See Harstad (2010) and Konrad and Thum (forthcoming).

${ }^{16}$ See Golombek and Hoel $(2005,2011)$ for international agreements and cooperation on investments in technology when technology investments have spillover effects.

${ }^{17}$ Note that we abstract from discounting. One can argue that discounting is already captured by the difference in marginal contribution $\operatorname{costs} c_{t}$ and $c_{t+1}$ necessary to produce one contribution unit.
} 
Here, function $f$ translates climate protection effort into a mitigation outcome. As usual, $f$ is assumed to be strictly increasing and concave, $f^{\prime}>0, f^{\prime \prime}<0 .{ }^{18}$

Countries only differ in their valuation of the public good, denoted by $\theta^{A}$ and $\theta^{B}$. The heterogeneity in $\theta$ captures all country differences in the cost-benefit ratio of climate protection efforts (hence including differences in the cost of effort). These country-specific valuations of the public good are independent draws from two commonly known continuous distribution functions $\Phi_{A}$ and $\Phi_{B}$ with support $[0, \bar{\theta}]$. The functions $\Phi_{A}$ and $\Phi_{B}$ are assumed to be continuously differentiable on $(0, \bar{\theta})$.

In period $t$, there is uncertainty about the valuation of the public good $\theta^{i}$, which will be resolved in period $t+1$; consequently, both countries' valuations $\theta^{A}$ and $\theta^{B}$ become commonly known only between periods $t$ and $t+1$. Overall, no country has private information about its benefit from climate policy: country-specific differences with respect to cost and benefit of climate protection are typically observed. ${ }^{19}$ The uncertainty in the model, thus, reflects the difficulty of assessing the cost-benefit ratio and, hence, the valuation of climate protection. ${ }^{20}$

We will restrict the analysis to probability distributions with the following reverse hazard rate:

Assumption 1: $\quad \frac{\Phi_{i}^{\prime}(\theta)}{\Phi_{i}(\theta)} \leq \frac{1}{\theta}$ for all $\theta \in(0, \bar{\theta}], \quad i=A, B$.

This assumption ensures that the countries' maximization problems in period $t$ are wellbehaved and that the objective function is concave. ${ }^{21}$

The aspect of the irreversibility of foregone climate efforts is reflected in the contribution costs. A general increase in average world temperature cannot be easily reduced, regardless of how advanced the abatement technology is. $\mathrm{CO}_{2}$ stocks in the atmosphere dissipate very slowly and their impact can have considerable effects on the ecosystem. Counteracting deforestation is a slow and costly process. Furthermore, other environmental damages like acidified rain and lakes can have considerable irreversible consequences. Thus, due to the irreversibility of damages, delaying mitigation efforts may make future climate policy more

\footnotetext{
${ }^{18}$ To simplify the exposition, we will assume that $\theta f^{\prime}(0)$ is sufficiently large for all $\theta>0$ to ensure that all types $\theta>0$ will prefer a strictly positive total amount of the public good.

${ }^{19}$ Research on the impact of climate change such as the studies by the IPCC and UNFCCC is usually publicly accessible. There are extensive studies on the impact of climate change on various regions with detailed analysis that clearly shows the different possible outcomes of climate change by regions.

${ }^{20}$ For example, in a review of impact estimates of climate change, Jamet and Corfee-Morlot (2009) identify five sources of uncertainty: greenhouse gas emission projections, the accumulation of emissions in the atmosphere and how these emissions affect global temperatures, the physical impacts of a given increase in temperature, the valuation of physical impacts in terms of GDP and the risk of abrupt climate change.

${ }^{21}$ Note that, for instance, uniform or exponential probability distributions fulfill Assumption 1. This assumption is sufficient but not necessary for obtaining our results, and it simplifies the equilibrium analysis considerably.
} 
expensive. ${ }^{22}$ Therefore, we assume that the contribution cost in $t+1$ per unit of mitigation outcome is strictly larger than contribution cost in $t$ per unit of mitigation outcome,

$$
c_{t+1}(\kappa)>c_{t}(\kappa) \text {. }
$$

Our main analysis considers the effects of an investment in cost-reducing technology on the equilibrium climate protection outcome. We focus on the notion that investments in climate abatement technology are shared. Generally, successful investments in R\&D have strong spillover effects, for example, through trade magazines and reverse engineering by competitors. In addition, patent protection for new inventions and innovations only have a limited time frame. Furthermore, in the case of climate abatement technology, such spillovers are more strongly encouraged through large technology transfer initiatives. Thus, we consider investments in cost-reducing technology $\kappa \in\left[\kappa_{0}, \infty\right)$ which affect the marginal costs of both countries in the same way. ${ }^{23}$ Notice that $\kappa_{0}$ denotes the initial technology in use. ${ }^{24}$ Without explicitly modeling investments in technology, we analyze whether or not, at the beginning of period $t$, an improvement of the available technology will change the structure of the equilibrium contributions. We only consider the case where an improvement in technology (weakly) reduces both periods' marginal contribution cost, that is,

$$
\frac{\partial c_{t}(\kappa)}{\partial \kappa} \leq 0 \text { and } \frac{\partial c_{t+1}(\kappa)}{\partial \kappa} \leq 0
$$

Our analysis solves for the subgame-perfect Nash equilibrium of the following game. ${ }^{25}$ In stage 0, nature independently draws the country-specific valuations of the public good from the distribution functions $\Phi_{A}$ and $\Phi_{B}$, which are common knowledge. Then, countries might invest in a cost-decreasing technology. In stage 1 countries $A$ and $B$ simultaneously

\footnotetext{
${ }^{22}$ This assumption is built on the fact that $\mathrm{CO}_{2}$ is a stock pollutant and hence current emissions cause long-term costs. For an economic analysis of the cost of stabilization of $\mathrm{CO}_{2}$ concentration see Chapters 9-11 of the Stern Review (2007) and the discussion in Mendelsohn (2008) and Dietz and Stern (2008).

${ }^{23}$ From a country perspective, these costs could also take the form of a subsidy to be paid to firms in order to induce them to invest in green technology and to share the technology with other countries/firms.

${ }^{24}$ For simplicity, we assume that technology $\kappa$ is not restricted. Of course, one can assume that $\kappa$ is bounded to a certain level $\kappa_{\text {max }}$ due to cost considerations, this, however, would not qualitatively change our results.

${ }^{25}$ In the game specified, no player has private information about his type at any point in time, but each player's type is only revealed after period $t$. Hence, to be precise, a complete characterization of the equilibrium would require specification of the players' beliefs about their own and their co-player's type. In our equilibrium analysis, we implicitly assume that, in period $t$, each player $i=A, B$ believes that his and his co-player's type are drawn from the distributions $\Phi_{A}$ and $\Phi_{B}$, respectively, and we solve for the perfect Bayesian equilibrium under these beliefs. In period $t+1$, both types become common knowledge, and, thus, updating of beliefs does not play a role in our framework. For simplicity, we omit this more complex notation.
} 
choose their contributions $x_{t}^{A}$ and $x_{t}^{B}$. Then, both contributions and the country-specific valuations of the public good become publicly observable. Finally, in stage 2 countries, again simultaneously, choose their contributions $x_{t+1}^{A}$ and $x_{t+1}^{B}$, and payoffs are realized.

\section{Contributions to Climate Protection}

In this section, we characterize the countries' equilibrium contributions in the two periods (stages 1 and 2). In each period, the two countries $A$ and $B$ simultaneously decide over their contributions to the public good. The countries' contributions are strategic substitutes, and, as we will show, the countries' optimal contributions depend not only on incentives to free-ride on the other country's (current and future) contributions but also on the trade-off between uncertainty and irreversibility of damages. We solve the game through backward induction.

\subsection{Preferred provision levels in period $t+1$}

Consider first period $t+1$. Here, the countries' valuations $\theta^{A}$ and $\theta^{B}$ are common knowledge and the game is strategically equivalent to a standard private provision game with a given contribution $X_{t}=x_{t}^{A}+x_{t}^{B}{ }^{26}$ We define a country $i$ 's preferred provision level of the public good in $t+1$ as the quantity $Q_{t+1}^{i}\left(\theta^{i}\right)$ that solves $i$ 's first order condition

$$
\theta^{i} f^{\prime}\left(Q_{t+1}^{i}\left(\theta^{i}\right)\right)-c_{t+1}=0,
$$

that is

$$
Q_{t+1}^{i}\left(\theta^{i}\right):=\left\{\begin{array}{cc}
\left(f^{\prime}\right)^{-1}\left(c_{t+1} / \theta^{i}\right) & \text { if } \theta^{i}>0 \\
0 & \text { otherwise. }
\end{array}\right.
$$

$Q_{t+1}^{i}\left(\theta^{i}\right)$ denotes the level of contributions up to which $i$ would like to increase total contributions. Notice that a country might only contribute a strictly positive amount in period $t+1$ if the total period $t$ contributions $X_{t}$ are lower than $Q_{t+1}^{i}\left(\theta^{i}\right)$. Moreover, due to the quasi-linear payoff functions, in equilibrium one country at most will contribute in period $t+1$; this country will be the country $i$ with the higher preferred provision level $Q_{t+1}^{i}\left(\theta^{i}\right)$ or, equivalently, the country $i$ with the higher valuation $\theta^{i}$ for the public good. ${ }^{27}$ This country $i$ raises the contribution level up to its desired quantity $Q_{t+1}^{i}\left(\theta^{i}\right)$, and country $j \neq i$ free-rides

\footnotetext{
${ }^{26}$ Recall that the marginal contribution cost is constant.

${ }^{27}$ This is in line with the standard text book result for public goods models with quasi-linear utility functions; comparing the first order condition of both players, it becomes clear that the equilibrium must be at a corner solution.
} 
and contributes zero. ${ }^{28}$ Hence, the equilibrium contributions are given by

$$
\left(x_{t+1}^{A}, x_{t+1}^{B}\right)^{*}=\left\{\begin{array}{cl}
\left(\max \left\{Q_{t+1}^{A}\left(\theta^{A}\right)-X_{t}, 0\right\}, 0\right) & \text { if } \theta^{A}>\theta^{B} \\
\left(0, \max \left\{Q_{t+1}^{B}\left(\theta^{B}\right)-X_{t}, 0\right\}\right) & \text { if } \theta^{A}<\theta^{B}
\end{array}\right.
$$

\subsection{Preferred provision levels in period $t$}

Inserting the equilibrium contributions in period $t+1$ into country $i$ 's decision problem in period $t$, country $i$ chooses $x_{t}^{i}$ to maximize its expected payoff $\pi_{i}\left(x_{t}^{i}\right)$, given $\left(x_{t+1}^{A}, x_{t+1}^{B}\right)^{*}$ and given $x_{t}^{j}$. Hence, $\pi_{i}\left(x_{t}^{i}\right)$ is equal to

$$
\begin{aligned}
& \int_{0}^{\bar{\theta}} \int_{0}^{\theta^{i}}\left(\theta^{i} f\left(\max \left\{Q_{t+1}^{i}, X_{t}\right\}\right)-c_{t} x_{t}^{i}-c_{t+1} \max \left\{Q_{t+1}^{i}-X_{t}, 0\right\}\right) d \Phi_{j}\left(\theta^{j}\right) d \Phi_{i}\left(\theta^{i}\right) \\
& +\int_{0}^{\bar{\theta}} \int_{\theta^{i}}^{\bar{\theta}}\left(\theta^{i} f\left(\max \left\{Q_{t+1}^{j}, X_{t}\right\}\right)-c_{t} x_{t}^{i}\right) d \Phi_{j}\left(\theta^{j}\right) d \Phi_{i}\left(\theta^{i}\right) .
\end{aligned}
$$

Taking contributions in period $t+1$ into account, country $i$ weighs the expected probabilities of two possible cases: the case where it turns out that it has the higher valuation in period $t+1$ than country $j$ (the first integral in (4)), and the case where it has a lower valuation than country $j$ (the second integral in (4)).

In both cases $\left(\theta^{i}>\theta^{j}\right.$ and $\left.\theta^{i}<\theta^{j}\right)$, apart from the realization of the valuations $\theta^{i}$ and $\theta^{j}$, potential contributions in period $t+1$ will depend on the amount $X_{t}$ that has already been contributed in period $t$, since a country $k \in\{A, B\}$ might only contribute in period $t+1$ if its preferred provision level $Q_{t+1}^{k}$ is strictly larger than $X_{t}$. Using (2) and the fact that $Q_{t+1}^{i}(\theta)$ is strictly increasing in $\theta$ we can define by

$$
\hat{\theta}:=\frac{c_{t+1}}{f^{\prime}\left(X_{t}\right)}
$$

the critical valuation for which a country's preferred provision level in $t+1$ is exactly equal to $X_{t}$. Consequently, only countries with a realized valuation $\theta>\hat{\theta}$ may contribute in $t+1$.

Now consider country $i$ 's expected marginal payoff of an increase in $x_{t}^{i}$. Suppose first that the given total contribution $X_{t}$ is smaller than $Q_{t+1}^{i}(\bar{\theta})$ (where $Q_{t+1}^{i}(\bar{\theta})$ is the preferred provision level in $t+1$ of the type with the highest possible valuation $\bar{\theta}$ ). In this case, contributions in $t+1$ occur with strictly positive probability, and $i$ 's marginal expected

\footnotetext{
${ }^{28}$ If $\theta^{A}=\theta^{B}$ and $Q_{t+1}^{i}>X_{t}$, there is a continuum of equilibria with $\left(x_{t+1}^{A}\right)^{*}+\left(x_{t+1}^{B}\right)^{*}=Q_{t+1}^{i}-X_{t}$. For completeness, we assume that in this case the symmetric equilibrium is played, although $\theta^{A}=\theta^{B}$ occurs with probability zero (due to the assumption of continuous distribution functions $\Phi_{A}$ and $\Phi_{B}$ ).
} 
payoff of an increase in $x_{t}^{i}$ is equal to ${ }^{29}$

$$
\begin{aligned}
\pi_{i}^{\prime}\left(x_{t}^{i} ; X_{t}<Q_{t+1}^{i}(\bar{\theta})\right)= & \int_{0}^{\hat{\theta}} \int_{0}^{\hat{\theta}}\left(\theta^{i} f^{\prime}\left(X_{t}\right)-c_{t}\right) d \Phi_{j}\left(\theta^{j}\right) d \Phi_{i}\left(\theta^{i}\right) \\
& +\int_{\hat{\theta}}^{\bar{\theta}} \int_{0}^{\theta^{i}}\left(c_{t+1}-c_{t}\right) d \Phi_{j}\left(\theta^{j}\right) d \Phi_{i}\left(\theta^{i}\right) \\
& +\int_{0}^{\bar{\theta}} \int_{\max \left\{\theta^{i}, \hat{\theta}\right\}}^{\bar{\theta}}\left(-c_{t}\right) d \Phi_{j}\left(\theta^{j}\right) d \Phi_{i}\left(\theta^{i}\right) .
\end{aligned}
$$

This marginal expected payoff in (6) consists of three terms representing three different cases: First, if both countries' realized valuations are smaller than the critical valuation $\hat{\theta}$, then no contribution will take place in $t+1$. Hence, with the probability that $\theta^{i} \leq \hat{\theta}$ and $\theta^{j} \leq \hat{\theta}$, country $i$ 's marginal payoff of increasing the period $t$ contribution is the difference between the marginal benefit of public good consumption and the marginal contribution cost in $t$ (the first term in (6)).

Otherwise, if $i$ 's realized valuation is greater than the critical valuation, i.e., $\theta^{i}>\hat{\theta}$, then $i$ would, in principle, be willing to make a contribution in $t+1$, and its equilibrium contribution in $t+1$ will depend on whether $j$ has a lower or higher valuation for climate protection. Accordingly, the second term in (6) reflects the case where $\theta^{i}>\theta^{j}$ and hence $i$ 's equilibrium contribution in $t+1$ is strictly positive. With the probability that $\theta^{i}>\hat{\theta}$ and $\theta^{i}>\theta^{j}$, the marginal payoff of increasing the period $t$ contribution is equal to the difference in the contribution costs, $c_{t+1}-c_{t}$ : by increasing the period $t$ contribution, country $i$ will save the higher contribution cost in $t+1$. The third term illustrates $i$ 's marginal payoff given that country $j$ has a higher valuation (and $\theta^{j}>\hat{\theta}$ ); in this case, country $i$ 's marginal benefit of increasing the period $t$ contribution is zero because this contribution would have been made by $j$ in period $t+1$ anyway, and a contribution only bears the marginal cost $c_{t}$.

Altogether, the three terms illustrate the trade-off between uncertainty (unknown realization of the valuation) and irreversibility (higher contribution cost in $t+1$ ) on the one hand and the incentives to free-ride on the other hand. While the effect of irreversibility in the second term in (6) is always positive and the free-riding effect in the third term is always negative, the sign of the first term depends on $X_{t}$. More precisely, the integrand in the first term in (6) is small and possibly negative for low realizations $\theta^{i}$ and increasing in $\theta^{i}$.

If total contributions $X_{t}=x_{t}^{A}+x_{t}^{B}$ are sufficiently high, they will crowd out all potential contributions in period $t+1: X_{t} \geq Q_{t+1}^{i}(\bar{\theta})$ is equivalent to $\hat{\theta} \geq \bar{\theta}$, and $i$ 's marginal payoff

\footnotetext{
${ }^{29}$ For more details see the proof of Lemma 1 in the appendix.
} 
of an increase in $x_{t}^{i}$ reduces to

$$
\pi_{i}^{\prime}\left(x_{t}^{i} ; X_{t} \geq Q_{t+1}^{i}(\bar{\theta})\right)=\int_{0}^{\bar{\theta}} \int_{0}^{\bar{\theta}}\left(\theta^{i} f^{\prime}\left(X_{t}\right)-c_{t}\right) d \Phi_{j}\left(\theta^{j}\right) d \Phi_{i}\left(\theta^{i}\right) .
$$

Regardless of which valuation is revealed in period $t+1$, no contribution will take place; consequently, considerations with regard to a potential cost or saving of a contribution in period $t+1$ do not play a role. The expected marginal benefit of further increasing $x_{t}^{i}$ is simply equal to $E\left(\theta^{i}\right) f^{\prime}\left(X_{t}\right)$ and the marginal cost is $c_{t}$.

Optimizing over $x_{t}^{i}$ yields a preferred provision level $Q_{t}^{i}$ in period $t$ for country $i \in\{A, B\}$, taking into account that equilibrium contributions in $t+1$ are as in (3). Notice that $Q_{t}^{i}>0$ does not imply that $i$ 's equilibrium contribution $\left(x_{t}^{i}\right)^{*}$ must necessarily be positive. Rather, $Q_{t}^{i}$ is the quantity that $i$ would contribute to the public good in period $t$ if $j$ does not contribute. Compared to country $i$ 's preferred contribution level in period $t+1$, which directly depends on $\theta^{i}$, the preferred level $Q_{t}^{i}$ of period $t$ depends on $i$ 's expectations of the realizations of $\theta^{i}$ and $\theta^{j}$ and the corresponding equilibrium contributions in $t+1$. The following lemma characterizes each country's preferred period $t$ provision level. It is assumed, as for all following statements, that Assumption 1 holds.

Lemma 1 Consider the quantity of the public good that country $i \in\{A, B\}$ would prefer to be provided in period $t$.

(i) Suppose that $E\left(\theta^{i}\right) / \bar{\theta} \geq c_{t} / c_{t+1}$. Then country $i$ 's preferred provision level in period $t$ is equal to $Q_{t}^{i}=\left(f^{\prime}\right)^{-1}\left(c_{t} / E\left(\theta^{i}\right)\right) \geq Q_{t+1}^{i}(\bar{\theta})$.

(ii) Suppose that $E\left(\theta^{i}\right) / \bar{\theta}<c_{t} / c_{t+1}$.

(a) If

$$
E\left(\Phi_{j}\left(\theta^{i}\right)\right) \leq \frac{c_{t}}{c_{t+1}}
$$

then country i's preferred provision level in period $t$ is equal to $Q_{t}^{i}=0$.

(b) If

$$
E\left(\Phi_{j}\left(\theta^{i}\right)\right)>\frac{c_{t}}{c_{t+1}}
$$

then country $i$ 's preferred provision level in period $t$ is uniquely determined with $Q_{t}^{i} \in\left(0,\left(f^{\prime}\right)^{-1}\left(c_{t} / E\left(\theta^{i}\right)\right)\right)$.

The idea behind Lemma 1 is straightforward. In Lemma 1(i), if the expected to maximum valuation ratio $E\left(\theta^{i}\right) / \bar{\theta}$ is higher than the cost ratio $c_{t} / c_{t+1}$, then country $i$ prefers a 
provision level in $t$ that is sufficiently high to crowd out all further contributions in $t+1$. (Here, $Q_{t}^{i}$ is higher than $Q_{t+1}^{i}(\bar{\theta})$, which is the preferred period $t+1$ provision level for the highest possible valuation.) In this case, $Q_{t}^{i}$ is determined irrespective of period $t+1$ and, hence, country $i$ equates marginal cost and benefit from contributing based on its expected valuation. We will refer to such a situation as the case of a "full" preferred provision level in period $t$, and it occurs if the expected valuation and/or the degree of irreversibility is high (where the degree of irreversibility can be measured as the inverse cost ratio $c_{t+1} / c_{t}$ ).

If, however, $E\left(\theta^{i}\right) / \bar{\theta}$ is lower than the cost ratio $c_{t} / c_{t+1}$, then country $i$ will never want a full provision in period $t$ already. In this case, $\pi_{i}^{\prime}\left(0 ; X_{t}=0\right) \leq 0$, or $(8)$, is sufficient to ensure that country $i$ does not want to contribute in $t$, independent of $x_{t}^{j}$. This leads to Lemma 1(ii)a. ${ }^{30}$ By the same argument, if instead $\pi_{i}^{\prime}\left(0 ; X_{t}=0\right)>0$, or $(9)$, then country $i$ prefers a strictly positive provision level $Q_{t}^{i}$ in period $t$. Here, country $i$ prefers only a "partial" provision in period $t$, accepting that, depending on the true valuations, it might contribute again in $t+1$ (Lemma $1(\mathrm{ii}) \mathrm{b}) \cdot{ }^{31}$

Which country prefers a higher public good provision in period $t$ ? The mechanism of a standard private provision game persists in the contribution decision of period $t$. Due to the quasi-linear payoff functions, positive contributions by either country are perfect substitutes. Thus, if both countries prefer a strictly positive contribution level in $t$, i.e., if $Q_{t}^{A}>0$ and $Q_{t}^{B}>0$, then, in equilibrium, only the country $i$ with the higher preferred contribution level $Q_{t}^{i}>Q_{t}^{j}$ will contribute in $t$. Concretely, this country will contribute exactly $\left(x_{t}^{i}\right)^{*}=Q_{t}^{i}$, and the other country will contribute zero in period $t$.

Before turning to the characterization of the equilibrium, let us consider in more detail the determinants of whether $Q_{t}^{i}>Q_{t}^{j}$, which are implied by Lemma 1. If both countries prefer a full provision in period $t$ (as in Lemma 1(i)), the country with the higher expected valuation will bear the contribution cost since the preferred quantity is increasing in $E(\theta)$; hence $i$ prefers a higher quantity if and only if $E\left(\theta^{i}\right)>E\left(\theta^{j}\right)$. If one country $i$ prefers a full provision and the other country $j$ prefers a partial provision level in period $t$, this implies that $E\left(\theta^{i}\right) / \bar{\theta} \geq c_{t} / c_{t+1}>E\left(\theta^{j}\right) / \bar{\theta}$ and thus in this case country $i$, with $E\left(\theta^{i}\right)>E\left(\theta^{j}\right)$, is again the country that prefers the higher provision level. ${ }^{32}$

\footnotetext{
${ }^{30}$ In Lemma 1(ii)a, if (8) holds with equality and Assumption 1 holds with equality on some non-empty interval $\left[0, \theta^{\prime}\right]$, then $i$ is indifferent between all $Q_{t}^{i} \in\left[0,\left(f^{\prime}\right)^{-1}\left(c_{t+1} / \theta^{\prime}\right)\right]$ (see Appendix). To simplify the exposition, Lemma 1(ii)a assumes that in this case $Q_{t}^{i}=0$. If Assumption 1 holds with strict inequality, then $Q_{t}^{i}=0$ if and only if (8) is fulfilled.

${ }^{31}$ Note that $E\left(\theta^{i} / \bar{\theta}<c_{t} / c_{t+1}\right.$ implies that $\left(f^{\prime}\right)^{-1}\left(c_{t} / E\left(\theta^{i}\right)\right)<Q_{t+1}^{i}(\bar{\theta})$. Hence, in Lemma 1(ii)b, $Q_{t}^{i}<$ $Q_{t+1}^{i}(\bar{\theta})$ and the highest type's preferred quantity in $t+1$ is strictly higher than what $i$ prefers to be contributed in $t$.

${ }^{32}$ This holds due to $Q_{t}^{j} \leq\left(f^{\prime}\right)^{-1}\left(c_{t} / E\left(\theta^{j}\right)\right)<\left(f^{\prime}\right)^{-1}\left(c_{t} / E\left(\theta^{i}\right)\right)=Q_{t}^{i}$.
} 
In the case where both countries prefer a "partial provision" in period $t$ (Lemma 1(ii)b), the comparison of the expected valuations is no longer sufficient to determine which country prefers a higher quantity to be provided in $t$. Here, country $A$ prefers a higher "partial provision" in $t$ if the difference between the countries' marginal payoffs of contributing in $t$, $\pi_{A}^{\prime}\left(X_{t}\right)-\pi_{B}^{\prime}\left(X_{t}\right)$, is strictly positive at $X_{t}=Q_{t}^{B}$, thus, if

$$
\begin{aligned}
& \Phi_{A}(\hat{\theta}) \Phi_{B}(\hat{\theta})\left[E\left(\theta^{A} \mid \theta^{A} \leq \hat{\theta}\right)-E\left(\theta^{B} \mid \theta^{B} \leq \hat{\theta}\right)\right] f^{\prime}\left(X_{t}\right) \\
& +c_{t+1}\left[\int_{\hat{\theta}}^{\bar{\theta}} \Phi_{B}\left(\theta^{A}\right) d \Phi_{A}\left(\theta^{A}\right)-\int_{\hat{\theta}}^{\bar{\theta}} \Phi_{A}\left(\theta^{B}\right) d \Phi_{B}\left(\theta^{B}\right)\right]>0
\end{aligned}
$$

holds at $X_{t}=Q_{t}^{B}$ (which implies $\hat{\theta}=c_{t+1} / f^{\prime}\left(Q_{t}^{B}\right)$ in (10)). As condition (10) reveals, differences in the countries' preferred provision levels in period $t$ are driven by two comparisons: first, by differences in the expected benefit from contributing, conditional on there being no further contributions in $t+1$ (the first term: conditional expected valuation multiplied by $f^{\prime}\left(X_{t}\right)$ ), and second, by differences in the expected equilibrium contribution cost in period $t+1$ (the second term: $c_{t+1}$ multiplied by the probability that this cost has to be paid). Without making further assumptions on the cumulative distribution functions, it is not straightforward when condition (10) holds. However, if $\pi_{i}^{\prime}\left(X_{t}\right)-\pi_{j}^{\prime}\left(X_{t}\right)>0$ for all $X_{t} \geq 0$, it is clear that country $i$ will have a higher preferred contribution level. This is the case, for instance, if the countries' distributions of the valuations can be ranked according to first-order stochastic dominance. In general, however, the first and the second term in (10) do not need to have the same sign, and whether $Q_{t}^{A}>Q_{t}^{B}$ will also depend on $f^{\prime}$ and $c_{t+1}$.

\subsection{Equilibrium contributions}

The equilibrium contributions in period $t$ follow directly from the analysis above, which is summarized in the following proposition.

Proposition 1 The countries' equilibrium contributions in period t are determined such that

(i) if $Q_{t}^{A}=Q_{t}^{B}=0$, then $\left(x_{t}^{A}\right)^{*}=\left(x_{t}^{B}\right)^{*}=0$,

(ii) if $Q_{t}^{A}>Q_{t}^{B} \geq 0$, then $\left(x_{t}^{A}\right)^{*}=Q_{t}^{A}$ and $\left(x_{t}^{B}\right)^{*}=0$,

(iii) if $Q_{t}^{B}>Q_{t}^{A} \geq 0$, then $\left(x_{t}^{A}\right)^{*}=0$ and $\left(x_{t}^{B}\right)^{*}=Q_{t}^{B}$,

(iv) if $Q_{t}^{A}=Q_{t}^{B}>0$, then there is a continuum of equilibria with $\left(x_{t}^{A}\right)^{*}+\left(x_{t}^{B}\right)^{*}=Q_{t}^{A}$, where the countries' preferred provision levels $Q_{t}^{A}$ and $Q_{t}^{B}$ are given in Lemma 1. 
Proposition 1 results directly from Lemma 1; hence, a proof is omitted. If the degree of irreversibility is low and hence the cost ratio $c_{t} / c_{t+1}$ is close to 1 (to be precise, if $c_{t} / c_{t+1}$ is larger than $\max \left\{E\left(\Phi_{j}\left(\theta^{i}\right)\right), E\left(\theta^{i}\right) / \bar{\theta}\right\}$; compare Lemma 1), then both countries prefer not to contribute in $t$ but instead to wait until period $t+1$ (case (i)). Total expected contributions to the public good are then equal to

$$
E\left(X_{t+1}\right)=E_{\theta^{A}, \theta^{B}}\left[\max \left\{Q_{t+1}^{A}\left(\theta^{A}\right), Q_{t+1}^{B}\left(\theta^{B}\right)\right\}\right]
$$

since, in $t+1$, the country with the higher valuation will contribute its preferred provision level based on the contribution cost $c_{t+1}$.

For intermediate values of $c_{t} / c_{t+1}$, at least one country will prefer a positive provision level in $t$ (cases (ii) and (iii)), and only one country will contribute in $t$. For such intermediate irreversibility ratios, it is optimal to choose only a partial provision in period $t$, and there will be further contributions in $t+1$. When $c_{t+1}$ is high and, hence, the ratio $c_{t} / c_{t+1}$ is low, contributing in $t$ becomes even more attractive, and the country that contributes in $t$ will choose a full provision in $t$ that crowds out all possible contributions in $t+1$. Finally, if both countries prefer exactly the same (positive) provision level in $t$ (for instance, if $\Phi_{A}=\Phi_{B}$ ), then there is a continuum of equilibria where the countries' contributions in $t$ sum up to this preferred level (case (iv)).

The derived equilibrium contributions have several implications. First, it becomes clear that if there is a positive contribution to the public good in any period, then it will be borne by only one country (except for the special case in Proposition 1(iv)). Furthermore, the contribution decision is additionally affected by the possibility of "intertemporal freeriding". Depending on the degree of irreversibility $\left(c_{t+1} / c_{t}\right)$, the equilibrium contribution in the early period can be zero, a partial provision level or a full provision level which crowds out all further $t+1$ contributions.

\section{Isolating the effects on timing}

In the following, we isolate the different motivations that drive the timing of the countries' equilibrium contributions to climate protection.

The effects of uncertainty and irreversibility on the timing of the contribution. The analysis of the previous section has been crucially driven by the countervailing effects of uncertainty versus irreversibility. To further illustrate these effects, consider the case where there is uncertainty about the valuations for climate protection but no irreversibility 
of forgone efforts to climate protection. When $c_{t+1}$ approaches $c_{t}$, a contribution in $t$ is strictly dominated, independent of the remaining parameters of the model (for instance, the probability distributions $\Phi_{A}$ and $\left.\Phi_{B}\right)$. Both countries will prefer to wait until the resolution of the uncertainty. A standard game of private provision of a public good, based on the realized valuations, will ensue in period $t+1$. Uncertainty is the predominant effect in case (i) of Proposition 1.

Now consider instead the case where there is no uncertainty but irreversibility; that is, where the variance of $\Phi_{A}$ and $\Phi_{B}$ goes to zero but where the structure of the model remains unchanged. In the limit where the valuations are already known in period $t$, delaying the contribution until $t+1$ is strictly dominated, as contributions in $t+1$ cause a strictly higher marginal cost. Accordingly, both countries will want to contribute in period $t$ at the lower marginal cost $c_{t}$. This is comparable to cases (ii)-(iii) of Proposition 1, provided that the equilibrium contribution $\left(x_{t}^{i}\right)^{*}=Q_{t}^{i}$ ensures a full provision of the public good in $t$.

In summary, while uncertainty pushes the timing of the contribution to climate protection towards a later date, irreversibility pushes the timing towards an earlier date.

The effect of free-riding on the timing of the contribution. To isolate the effect of (intertemporal) free-riding on the optimal timing decision, consider the case in which there is only one country (here country $i$ ) that decides over its contribution to climate protection. The remaining structure of the model continues unchanged. Solving the model through backward induction, it is straightforward to see that the rationale driving the preferred provision level of period $t+1$ is identical to the two country case. The only difference is that the preferred provision level $Q_{t+1}^{i}\left(\theta_{i}\right)$ automatically constitutes the country's equilibrium contribution in $t+1$.

Now turn to country $i$ 's optimal decision in period $t$, taking into account that $\left(x_{t+1}^{i}\right)^{*}=$ $Q_{t+1}^{i}\left(\theta_{i}\right)$. Suppose that $i$ 's contribution in $t$ is smaller than $Q_{t+1}^{i}(\bar{\theta})$ which ensures a positive contribution in $t+1$ with strictly positive probability. Again, $\hat{\theta}=c_{t+1} / f^{\prime}\left(x_{t}^{i}\right)$ denotes the critical valuation below which there will be no contribution in $t+1$. In the one-country case, country $i$ 's marginal expected payoff from increasing the contribution in $t$ is equal to

$$
\pi_{i}^{\prime}\left(x_{t}^{i}\right)=\int_{0}^{\hat{\theta}}\left(\theta^{i} f^{\prime}\left(x_{t}^{i}\right)-c_{t}\right) d \Phi_{i}\left(\theta^{i}\right)+\int_{\hat{\theta}}^{\bar{\theta}}\left(c_{t+1}-c_{t}\right) d \Phi_{i}\left(\theta^{i}\right) .
$$

Let us compare this marginal payoff to the marginal payoff in the two-country case, as derived in (6). Similar to (6), the first term in (11) describes the marginal payoff if there is no contribution in $t+1$ (because $\theta^{i} \leq \hat{\theta}$ ). This marginal payoff also emerges in the twocountry case (the first term in (6)), but, there, only with the probability that $j$ also has a 
valuation below the critical valuation $\left(\theta^{j} \leq \hat{\theta}\right)$.

The second term in (11) represents the savings in marginal contribution cost in case $i$ 's valuation turns out to be high. In the one-country case, these savings are realized whenever $\theta^{i}>\hat{\theta}$, while in the two-country case, this positive effect on a period $t$ contribution also depends on whether or not $\theta^{j}<\theta^{i}$. In the two-country case, even if $i$ has a valuation above the critical valuation $\left(\theta^{i}>\hat{\theta}\right)$, this does not necessarily imply that it has to pay the high marginal cost $c_{t+1}$ because $j$ will bear the contribution cost if $\theta^{j}>\theta^{i}$; hence, in the twocountry case, the probability that these savings are realized is lower. Finally, the two-country case identifies an additional negative effect on the marginal payoff which corresponds to the possibility to free-ride and is not present in the one-country case (the third term in (6)). In the two-country case, if it turns out that the other country has a higher valuation, having increased the contribution in $t$ would have caused an unnecessary cost.

While the benefits from an early contribution in the two-country case are realized only with lower probability, the possibility of free-riding on the other country's future contribution adds a cost to a contribution in period $t$, which does not play a role in the one-country case. Consequently, the presence of another country and the strategic context of the public good problem cause a country's marginal payoff from an early contribution to be lower and, therefore, shift the timing of the contribution towards a later period..$^{33}$

\section{Investments in technology and the timing of contri- butions}

Having analyzed the equilibrium contributions, we can now turn to our main question and consider the effect of an exogenous investment in cost-reducing technology $\kappa$ on countries' timing of the contributions to climate protection. Recall that the cost-reducing technology $\kappa$ is defined such that an increase in $\kappa$ decreases the marginal contribution cost for both countries over both time periods. More specifically, the cost-reducing technology is denoted by $\kappa$, where $\kappa \in\left[\kappa_{0}, \infty\right)$ and $\kappa_{0}$ denotes the initial technology in use. We do not model the investment game explicitly but analyze the consequences for the equilibrium outcome as regards the timing of contributions. The results will directly clarify which country will have an incentive to invest in cost-reducing technology, provided that the cost of investing is sufficiently low compared to the benefit of investing.

Our analysis mainly focuses on situations where the irreversibility ratio $c_{t} / c_{t+1}$ is strictly decreasing over the interval $\left[\kappa_{0}, \infty\right)$ of possible technology levels. This is the case when an

\footnotetext{
${ }^{33}$ In this sense, the inclusion of a second country exhibits a similar free-riding rationale as derived in Admati and Perry (1991) and Fershtman and Nitzan (1991).
} 
investment in cost-reducing technology reduces the marginal contribution cost of period $t$ relatively more strongly than the marginal contribution cost of period $t+1 .{ }^{34}$ Intuitively, this can be interpreted as the notion that innovations in cost-reducing technology made today are more suited to tackle climate protection, given today's information, and that these technologies might be less effective with altered conditions or knowledge at a later date. For example, one can think of powerplants which are characterized by large sunk costs when investing in generation units. Their efficiency is highly sensitive to a changing regulatory framework, environment, and fuel prices; as such it is likely that investments in this technology relatively reduce the costs, given a certain regulatory framework and environment, in the early period more efficiently than in a later period.

In the next two subsections, we first analyze how an investment in cost-reducing technology affects the provision level and, then, we identify cases where such changes in the provision level lead to a change in the equilibrium outcome.

\subsection{Categorical changes in the period $t$ contributions}

In the following, we identify how investments in cost-reducing technology can effect a "categorical change" in the preferred provision levels $Q_{t}^{A}$ and $Q_{t}^{B}$. We consider "categorical changes" to be changes in the preferred provision levels in period $t$ which are linked with a change in the equilibrium contribution pattern. While marginal reductions in the contribution $\operatorname{costs} c_{t}$ and $c_{t+1}$ always (weakly) increase total contributions, we focus on "categorical changes" that affect one country's (or both countries') optimal timing of the contributions, i.e., that affect whether or not a country will choose a strictly positive contribution already in period $t$ and which type of early contribution is preferred. (An analysis of the marginal effects on already positive contribution levels is relegated to Appendix A.7.)

Proposition 2 Suppose that the irreversibility ratio $\gamma(\kappa):=c_{t}(\kappa) / c_{t+1}(\kappa)$ is strictly decreasing in $\kappa$. Then, there are two country-specific thresholds

$$
\kappa_{i}^{p}:=\gamma^{-1}\left(E\left(\Phi_{j}\left(\theta^{i}\right)\right)\right) \text { and } \kappa_{i}^{f}:=\gamma^{-1}\left(E\left(\theta^{i}\right) / \bar{\theta}\right)
$$

for country $i \in\{A, B\}$ such that

(i) if $\kappa<\kappa_{i}^{f}$ and $\kappa \leq \kappa_{i}^{p}$, then country $i$ prefers a provision $Q_{t}^{i}=0$ in period $t$,

\footnotetext{
${ }^{34}$ We concentrate our analysis on this type of investments in cost-reducing technologies as it is more in line with implemented technology transfer initiatives which focus on transferring green technologies to be used immediately. As it will become clear from the following analysis, it is easy to extend the analysis to the opposite scenarios and to consider incentives for technology sharing when investments in technology reduce the marginal contribution costs of period $t+1$ relatively more strongly.
} 
(ii) if $\kappa \geq \kappa_{i}^{f}$, then country $i$ prefers a full provision $Q_{t}^{i}=\left(f^{\prime}\right)^{-1}\left(c_{t} / E\left(\theta^{i}\right)\right)$ in period $t$,

(iii) if $E\left(\theta^{i}\right) / \bar{\theta}<E\left(\Phi_{j}\left(\theta^{i}\right)\right)$, then $\kappa_{i}^{p}<\kappa_{i}^{f}$ and country $i$ prefers a partial provision $Q_{t}^{i} \in\left(0,\left(f^{\prime}\right)^{-1}\left(c_{t} / E\left(\theta^{i}\right)\right)\right)$ in period $t$ for all $\kappa \in\left(\kappa_{i}^{p}, \kappa_{i}^{f}\right)$.

Whether or not a country wants to contribute to the public good in period $t$ crucially depends on the relation of the irreversibility ratio to the country's expected valuation and its expected probability of having the higher valuation. As Lemma 1 has revealed, the relation of the irreversibility ratio $c_{t} / c_{t+1}$ to the expected probability $E\left(\Phi_{j}\left(\theta^{i}\right)\right)$ of $i$ having a higher valuation than $j$ determines whether or not a country prefers a partial provision in $t$. The relation of $c_{t} / c_{t+1}$ to the expected to maximum valuation ratio, $E\left(\theta^{i}\right) / \bar{\theta}$, determines whether or not a country prefers a full provision of the public good in $t$. Thus, investments in technology can have an effect on the timing of the countries' contributions if they change the irreversibility ratio $c_{t}(\kappa) / c_{t+1}(\kappa)$. Proposition 2 identifies the country-specific technology thresholds under which such investments in technology alter the timing decision from no contribution to a positive provision level and from a partial preferred provision level to a full provision level. Notice that, for illustrational purposes, we have added the superscript $p$ and $f$ to the technology thresholds, to signal the type of period $t$ provision preferred by country $i$ : a partial or a full provision in period $t$.

For a shift of the contribution path towards an earlier provision, it is sufficient that the irreversibility ratio $c_{t}(\kappa) / c_{t+1}(\kappa)$ is strictly decreasing in $\kappa$ over the interval $\left[\kappa_{0}, \infty\right)$ of possible technology levels. This is the case if

$$
\left|\frac{\partial c_{t}}{\partial \kappa}\right|>\frac{c_{t}}{c_{t+1}}\left|\frac{\partial c_{t+1}}{\partial \kappa}\right|
$$

As $c_{t} / c_{t+1}<1$, even for the case when $\left|\partial c_{t+1} / \partial \kappa\right|>\left|\partial c_{t} / \partial \kappa\right|$, the relative costs of irreversibility can be perceived to be increasing, which strengthens the incentive for an early contribution. In other words, an absolute reduction of period $t+1$ marginal costs can be stronger than the absolute reduction of period $t$ marginal costs. Reducing $c_{t}$ always encourages an early contribution, while the lower marginal costs of a late contribution are realized only with a probability smaller than one (only if the country has the higher valuation).

For low technology levels where $\kappa<\kappa_{i}^{f}$ and $\kappa \leq \kappa_{i}^{p}$, the relative cost of waiting is not too high, and it is a strictly dominant strategy for country $i$ to wait until the uncertainty is resolved. For technology investments $\kappa_{i} \geq \kappa_{i}^{f}$, country $i$ prefers a full provision in period $t$ since the irreversibility ratio is smaller than $E\left(\theta^{i}\right) / \bar{\theta}$; this high contribution in $t$ crowds out any further contribution in $t+1$. For intermediate investment levels, due to the fact 


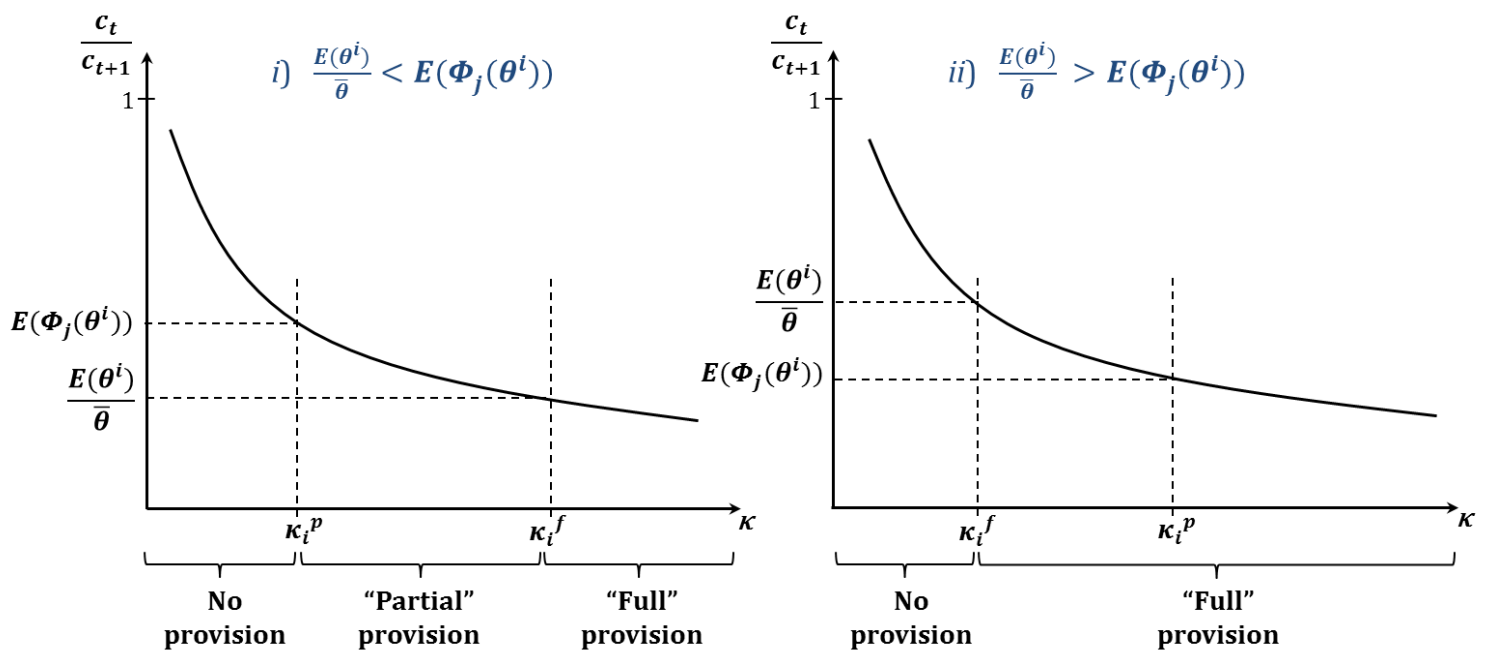

Figure 1: Country-specific technology thresholds for the preferred provision level in period $t$.

that $E\left(\theta^{i}\right) / \bar{\theta}$ can be smaller or larger than $E\left(\Phi_{j}\left(\theta^{i}\right)\right)$, we need to distinguish between two cases which are illustrated in Figure 1. If $E\left(\Phi_{j}\left(\theta^{i}\right)\right)>E\left(\theta^{i}\right) / \bar{\theta}$, then $\kappa_{i}^{p}<\kappa_{i}^{f}$ (compare Figure 1i)). In this case, there is a non-empty interval $\left(\kappa_{i}^{p}, \kappa_{i}^{f}\right)$ of technology levels where a partial provision in period $t$ is optimal for $i$. If instead $E\left(\Phi_{j}\left(\theta^{i}\right)\right) \leq E\left(\theta^{i}\right) / \bar{\theta}$, then $\kappa_{i}^{p} \geq \kappa_{i}^{f}$ (compare Figure 1ii)). In this case, $E\left(\Phi_{j}\left(\theta^{i}\right)\right)$ and the corresponding countryspecific technology threshold $\kappa_{i}^{p}$ is not relevant for $i$ 's period $t$ contribution decision, as country $i$ 's preferred provision level in $t$ will either be zero (if $\kappa<\kappa_{i}^{f}$ ) or, based on its expected valuation, the full amount $Q_{t}^{i}=\left(f^{\prime}\right)^{-1}\left(c_{t} / E\left(\theta^{i}\right)\right)$.

Hence, one can distinguish between two occasions that constitute a "categorical change" in the preferred provision levels. The first is an investment in cost-reducing technology which changes a country's preferred early provision from zero to a positive amount. The second occasion is an investment in cost-reducing technology which changes a country's preferred early provision level from a partial provision to a full provision. In both scenarios, investments in technology can have an impact on the determination of the country that, in equilibrium, pays the contribution cost of an early provision of the public good in $t$.

\subsection{Technology sharing to free-ride}

The assumption that all countries benefit from the cost reductions caused by investments in green technology adds an interesting layer to the analysis of the equilibrium contribution pattern. Countries can choose a cost-reducing technology level that shifts the equilibrium burden of contributing to the other country and allows the investing country to free-ride on 


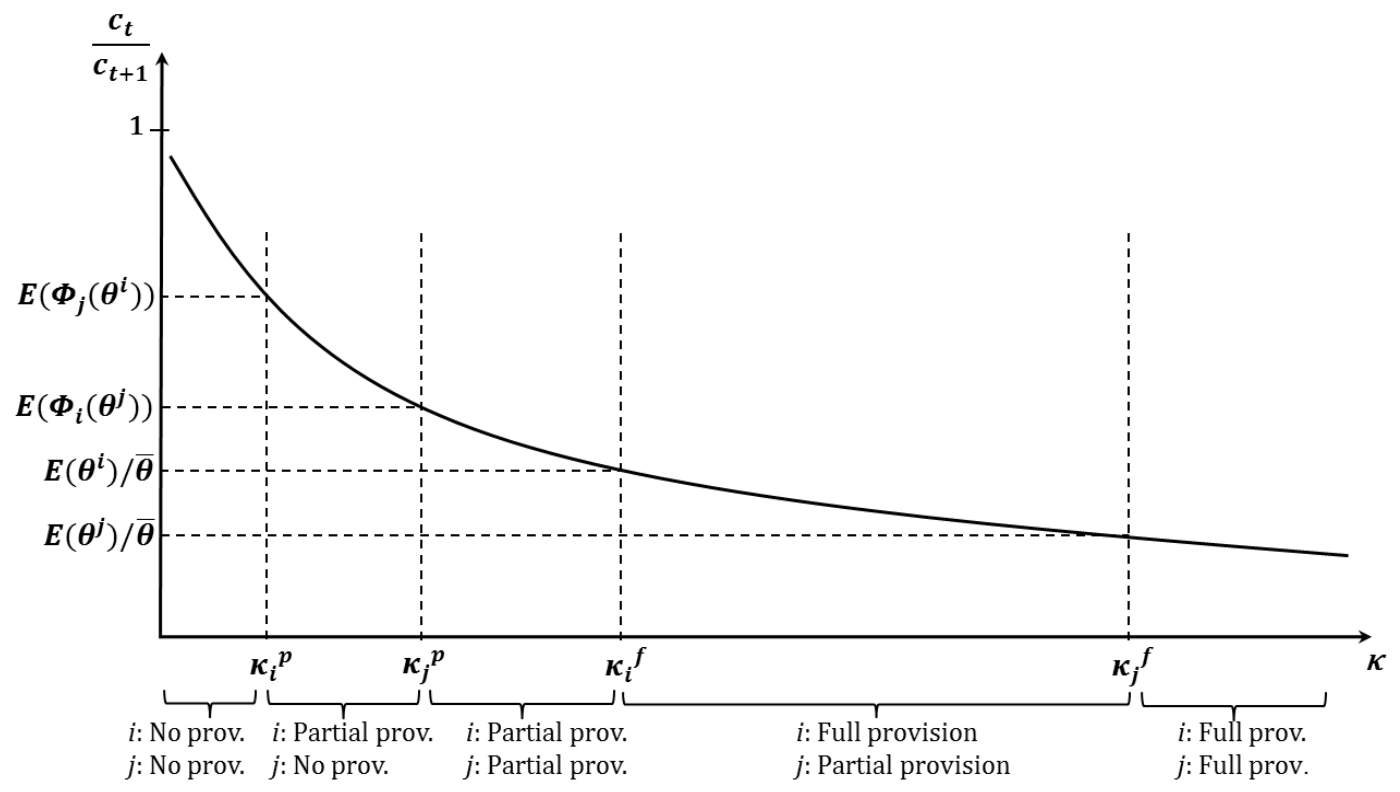

Figure 2: An example of categorical changes in the preferred period $t$ provision level.

the other country's contribution. We identify the two "free-riding scenarios" where a "categorical change" of the equilibrium contribution pattern occurs: a situation where otherwise no contributions take place in period $t$, and a situation where, in the equilibrium without investments in technology, one country already contributes in period $t$.

Given that the country-specific valuations for climate protection can be asymmetrically distributed in our model, it is clear that the thresholds $\kappa_{i}^{p}$ and $\kappa_{i}^{f}$ for $i=\{A, B\}$ (that is, the countries' incentives for an early contribution) can differ for the countries. A merging of Figure 1 for the two countries, thus, allows us to identify the irreversibility ratios and corresponding technology ranges that are connected with the different equilibrium candidates introduced in Proposition 1. An example is illustrated in Figure 2. In this example, the respective thresholds for country $i$ are lower than those for country $j$, implying that $i$ 's incentive to contribute early is stronger.

Scenario 1: no contributions in period t. First, we consider the countries' incentives to invest in technology in a situation where, without cost-reducing technology, there would be no contribution to the public good in period $t$, but both countries prefer to delay their contribution until period $t+1$. This occurs in equilibrium if

$$
\kappa_{0}<\min \left\{\kappa_{i}^{p}, \kappa_{i}^{f}\right\} \text { for } i=A, B
$$


that is, for both countries, $\kappa_{0}$ is smaller than the lowest technology level necessary to induce a positive early contribution.

Proposition 3 Suppose that $c_{t}(\kappa) / c_{t+1}(\kappa)$ is strictly decreasing in $\kappa$ and (12) holds such that, without investments in technology, equilibrium contributions in period t are zero. Define $i \in\{A, B\}$ and $j \neq i$ such that

$$
\max \left\{E\left(\Phi_{j}\left(\theta^{i}\right)\right), E\left(\theta^{i}\right) / \bar{\theta}\right\}>\max \left\{E\left(\Phi_{i}\left(\theta^{j}\right)\right), E\left(\theta^{j}\right) / \bar{\theta}\right\}
$$

Then, for all investments in cost-reducing technology with

$$
\kappa \in\left(\min \left\{\kappa_{i}^{p}, \kappa_{i}^{f}\right\}, \min \left\{\kappa_{j}^{p}, \kappa_{j}^{f}\right\}\right)
$$

the resulting equilibrium contributions in period $t$ satisfy $\left(x_{t}^{i}\right)^{*}>0$ and $\left(x_{t}^{j}\right)^{*}=0$.

Proposition 3 addresses the incentives to invest in cost-reducing technology in a situation where actually both countries prefer to delay their contribution to climate protection until period $t+1$. In this case, a targeted provision of cost-reducing technology $\kappa$ by country $j$ can raise country $i$ 's equilibrium contribution in period $t$ from zero up to a strictly positive amount, while country $j$ free-rides. Notice that the early contribution of $i$ strictly decreases the expected burden of contributing that both countries face in period $t+1$. The intuition behind this incentive to invest in cost-reducing technology hinges on the fact that countries are willing to endure different levels of the irreversibility ratio $c_{t} / c_{t+1}$ before they prefer to contribute in period $t$ already. Thus, there is a range $\left(\min \left\{\kappa_{i}^{p}, \kappa_{i}^{f}\right\}, \min \left\{\kappa_{j}^{p}, \kappa_{j}^{f}\right\}\right)$ of technology levels $\kappa$ where the irreversibility ratio decreases for both countries, but the preferred provision level in $t$ is raised from zero to a positive amount only for one country. ${ }^{35}$ Consequently, this opportunity to benefit from an early contribution of the other country exists for the country $j$ which needs a lower irreversibility ratio (cost ratio) to start developing a positive preferred period $t$ provision level (more precisely, $j \in\{A, B\}$ is defined according to (13)). Depending on the relation of $E\left(\Phi_{j}\left(\theta^{i}\right)\right)$ and $E\left(\theta^{i}\right) / \bar{\theta}$ of both countries, this will be the country with the lower expected valuation or the lower probability of learning to have the highest valuation. Notice that it is unnecessary to distinguish between the type of positive contribution reached: country $j$ benefits if $i$ chooses a partial or a full provision of the public good in period $t$. While Proposition 3 addresses the case where an investment in technology causes a "categorical change" in the preferred early contribution only for one country, the

\footnotetext{
${ }^{35}$ This effect cannot occur, of course, when countries are completely symmetric ex ante (i.e., their valuations are identically distributed).
} 
conditions given in Proposition 3 are sufficient but not necessary in the sense that very high levels of $\kappa$ can of course yield a similar effect on equilibrium contributions in period $t$.

Scenario 2: positive equilibrium contribution in period t. Now consider a situation where, without investment in technology, the equilibrium contributions to the public good are such that in period $t$ country $j$ contributes a positive amount, while country $i$ free-rides and contributes zero. Again, investments in technology can cause a "categorical change" in the equilibrium and lead to the opposite scenario where, in equilibrium, the previously non-contributing country $i$ is now contributing to climate protection.

A situation where, without investment in technology, equilibrium contributions are $\left(x_{t}^{i}\right)^{*}=$ 0 and $\left(x_{t}^{j}\right)^{*}>0$ emerges if

$$
\min \left\{\kappa_{j}^{p}, \kappa_{j}^{f}\right\}<\kappa_{0}<\min \left\{\kappa_{i}^{p}, \kappa_{i}^{f}\right\}, i \in\{A, B\}, j \neq i
$$

Here, without investments in technology, $i$ has a dominant strategy to delay its contribution (due to $\kappa_{0}<\min \left\{\kappa_{i}^{p}, \kappa_{i}^{f}\right\}$ ), but $j$ prefers a strictly positive contribution in $t$ (due to $\kappa_{0}>$ $\left.\min \left\{\kappa_{j}^{p}, \kappa_{j}^{f}\right\}\right)$.

Proposition 4 Suppose that $c_{t}(\kappa) / c_{t+1}(\kappa)$ is strictly decreasing in $\kappa$ and (14) holds such that, without investment in technology, country $j$ 's equilibrium contribution in $t$ is strictly positive.

(i) If $E\left(\theta^{i}\right)>E\left(\theta^{j}\right)$ and $E\left(\theta^{i}\right) / \bar{\theta} \geq E\left(\Phi_{j}\left(\theta^{i}\right)\right)$, then, for all investments in costreducing technology $\kappa \in\left[\kappa_{i}^{f}, \infty\right)$, the resulting equilibrium contributions in period $t$ satisfy $\left(x_{t}^{i}\right)^{*}>0$ and $\left(x_{t}^{j}\right)^{*}=0$.

(ii) If $E\left(\theta^{i}\right)>E\left(\theta^{j}\right)$ and $E\left(\theta^{i}\right) / \bar{\theta}<E\left(\Phi_{j}\left(\theta^{i}\right)\right)$, then there exists $\delta>0$ such that, for all investments in cost-reducing technology $\kappa \in\left(\kappa_{i}^{f}-\delta, \infty\right)$, the resulting equilibrium contributions in period $t$ satisfy $\left(x_{t}^{i}\right)^{*}>0$ and $\left(x_{t}^{j}\right)^{*}=0$.

The mechanism driving this proposition is straightforward: As above, an investment in cost-reducing technology that affects both countries may change the irreversibility ratio and, thus, elicit a different optimal response in the public good game. Country $j$ may initially prefer a partial contribution in period $t$ while $i$ prefers to wait, but a targeted choice of investments in technology alters the trade-off that each country faces. If country $i$ has the higher expected valuation $\left(E\left(\theta^{i}\right)>E\left(\theta^{j}\right)\right)$, a sufficiently high investment in technology will shift the burden of contributing to country $i$, in case both countries prefer an early contribution (based on their expected valuation). Proposition 4 again distinguishes whether 
or not $\kappa_{i}^{f} \leq \kappa_{i}^{p}$ (compare Figure 1). In part (i), $\kappa_{i}^{f} \leq \kappa_{i}^{p}$, and country $i$ prefers either a zero or a full contribution in period $t$; in this case, a technology level $\kappa \geq \kappa_{i}^{f}$ is necessary and sufficient to cause a situation where, in equilibrium, country $i$ chooses a strictly positive early contribution. In part (ii), $\kappa_{i}^{f}>\kappa_{i}^{p}$, and there exists a range of technology levels $\kappa$ where $i$ prefers a partial early provision. In this case, if $\kappa$ is lower but sufficiently close to $\kappa_{i}^{f}$, the period $t$ quantity preferred by $i$ is larger than the quantity preferred by $j$, and thus $i$ bears the burden of contributing early. Hence, there exists $\delta>0$ such that $i$ 's equilibrium contribution in period $t$ is strictly positive whenever $\kappa>\kappa_{i}^{f}-\delta$.

In this second scenario, summarized in Proposition 4, we capture a situation where the country that initially expects a higher potential saving from an early contribution is actually the country with the lower expected valuation for the public good. This country $j$ with the lower expected valuation can still have a stronger incentive to contribute early, since, when a country chooses a partial contribution in period $t$, it trades off the marginal benefit from an early contribution (depending on the expected valuation) and the expected marginal contribution cost in $t+1$, which depends on the probability that it turns out it has the higher valuation. Thus, as long as the countries' differences in the expected valuation for climate protection $\left(E\left(\theta^{i}\right)-E\left(\theta^{j}\right)\right)$ and the expected probability of having the higher valuation $\left(E\left(\Phi_{j}\left(\theta^{i}\right)\right)-E\left(\Phi_{i}\left(\theta^{j}\right)\right)\right)$ do not go in the same direction, a targeted reduction of the irreversibility ratio via cost-reducing technology $\kappa$ can result in a shift in the burden of the early contribution. ${ }^{36}$ The country $j$ with the lower expected value, which, for the initial degree of irreversibility, would prefer a positive early public good provision, can sufficiently increase its investments in cost-reducing technology so that the country $i$ with the higher expected value also prefers a positive early provision and contributes in equilibrium.

The results in Propositions 3 and 4 have direct implications for the effect of an investment in technology by country $j$ on the other country's payoff and on total payoffs. First of all, note that, in scenario 1 , country $i$ 's expected payoff increases if $j$ provides and transfers the new technology because $j$ 's early contribution is the same with and without technology investment (there is no crowding-out). And contributions of the "receiving" country $i$ are less costly based on the new technology $\kappa$. Thus, abstracting from direct cost of providing the technology, both countries are strictly better off. The set of equilibria of a strategic game of technology investments depends, of course, on additional assumptions on the technology production function (in particular, on potential spillover effects if both countries can choose positive investments). The fact that both countries benefit from the technology provision,

\footnotetext{
${ }^{36}$ Intuitively, this scenario can occur when the distribution function $\Phi_{i}$ with the higher expected value also exhibits thicker tails. An example for distribution functions with $E\left(\theta^{i}\right)>E\left(\theta^{j}\right)$ but $E\left(\Phi_{j}\left(\theta^{i}\right)\right)<E\left(\Phi_{i}\left(\theta^{j}\right)\right)$ is $\Phi_{i} \equiv \operatorname{Gamma}(1,3)$ and $\Phi_{j} \equiv \operatorname{Gamma}(0.5,4)$.
} 
however, directly implies that, depending on the cost of technology provision, a strategic game of technology investments (stage 0 ) has an equilibrium where $j$ provides a level of technology as in Proposition 3, which is then adopted by both countries.

In scenario 2, the investment in technology shifts the burden of an early contribution from $j$ to $i$; this has a negative effect on $i$ 's expected payoff, which is stronger the larger the amount $j$ would have contributed in period $t$ without investment in technology ${ }^{37}$ On the other hand, $i$ 's marginal contribution cost is reduced and the public good provision increases. Therefore, in scenario 2, country $i$ would join the technology transfer mechanism without additional incentives if and only if the positive effects of lower marginal cost and an increased public good provision outweigh the negative effect of an increased burden of contributing. Moreover, in both scenarios, the investing country $j$ is better off by providing the technology $\kappa$ if and only if the investment costs (the resources to be expended for developing a new technology) are sufficiently low (or, if there are benefits in addition to the increased climate protection). Consequently, a country might decide against adopting a new technology although technology sharing would increase total expected payoffs.

Welfare implications. Investments in technology have direct and indirect effects on $e x$ ante expected welfare being defined as the sum of the countries' expected payoffs. First, there is a direct cost in terms of resources to be expended for developing the technology, and there is a direct benefit in terms of reduced marginal contribution cost. In addition, however, there are indirect welfare effects from investments in technology in situations where the countries' timing of contributions is affected. As shown in Propositions 3 and 4, investments in technology can shift the countries' equilibrium contributions towards the early period. The direct effect of an increase in $\kappa$ is obvious; the following considerations isolate the indirect effect on the timing decisions. This timing effect alone has an impact on total expected equilibrium contributions to the public good and hence on welfare.

Corollary 1 Total expected equilibrium contributions are strictly increasing in the contribution $X_{t}^{*}$ in period $t$.

The result in Corollary 1 is straightforward: Higher early contributions strictly increase total equilibrium contributions to the public good. Intuitively, while higher early contributions just crowd out late contributions in case at least one country's valuation turns out to be high, there is no crowding out in case both $\theta^{A}$ and $\theta^{B}$ turn out to be low (both lower

\footnotetext{
${ }^{37}$ Note that $j$ 's contribution in case of $\kappa=\kappa_{0}$ (no investment in technology) is a "partial" provision.
} 
than the critical valuation $\hat{\theta}$, see $(5))$. Hence, overall we get

$$
\frac{\partial}{\partial X_{t}^{*}}\left(X_{t}^{*}+E\left(X_{t+1}^{*} \mid X_{t}^{*}\right)\right)=\Phi_{A}(\hat{\theta}) \Phi_{B}(\hat{\theta}) \geq 0
$$

with strict inequality for all $X_{t}^{*}>0$. Since $\hat{\theta}$ depends on $c_{t+1}$, this also takes into account that contributions in period $t+1$ are less likely due to the higher marginal cost. Thus, even disregarding the direct effect on the contribution costs, investments in technology cause total contributions to be higher when they affect the timing of contributing as in Propositions 3 and 4 . In turn, this effect on the countries' timing of contributing is also welfare-improving.

Corollary 2 Ex ante expected welfare is strictly increasing in the contribution $X_{t}^{*}$ in period $t$.

Corollary 2 addresses the indirect welfare effects of investments in technology caused by a change in the equilibrium contribution pattern (abstracting from direct cost effects). Here, even if higher early contributions lead-with higher probability-to an overcontribution from an individual country's point of view, a change in the countries' timing of the contributions in line with Propositions 3 and 4 increases welfare, because of two reasons. First, since, in equilibrium, there is underprovision of the public good, an increase in total contributions (as in Corollary 1) is welfare-improving. Second, in equilibrium, early contributions are inefficiently low due to 'intertemporal free-riding' (compare the discussion of the one-country case in Section 4); thus, increasing early contributions is again welfare-improving.

To summarize, investments in technology have direct costs and benefits, but, in addition, there are indirect effects caused by the impact on the countries' timing of equilibrium contributions: A shift towards early contributions increases welfare because it mitigates the underprovision problem. Even if the investment cost exceeds the investing country $j$ 's benefit from providing the technology or if the receiving country $i$ bears higher expected contribution costs, welfare can still be higher if investments in technology are carried out and technology transfer mechanisms are implemented. In such situations of a non-cooperative game of contributions to climate protection, the support of technology sharing mechanisms at the supranational level will be welfare-enhancing.

\section{Conclusion}

In this paper we have shown how the timing of the contribution to climate protection is affected by uncertainty, irreversibility, and the possibility to free-ride. Uncertainty about the country-specific benefit of climate protection creates an incentive to delay the contribution 
decision towards a later contribution date where the uncertainty is resolved, while the irreversibility of damages makes an earlier contribution more desirable. Furthermore, the fact that mitigation efforts are contributions to a global public good shifts the contribution more strongly towards a later contribution date, since, in anticipation of a free-riding possibility in the future, countries prefer to delay their contribution to climate protection. In other words, the positive externalities caused by investments in climate protection increase a country's option value of waiting. In such a situation, investments in cost-reducing technology have an important impact on the trade-off that countries face and, hence, on the timing of the contributions.

In the game of private contributions to the public good with potentially asymmetric but known valuations for climate protection, the country with the highest valuation for climate protection will face the major burden of contributing. The fact that countries have different expected probabilities of obtaining the higher valuation in the later period of the game makes them react differently to changes in the degree of irreversibility caused by investments in costreducing technology. The degree of irreversibility refers to the cost ratio of early and late contributions that are necessary to provide a marginal unit of the public good; the expected probability of having the higher valuation in the later period can be interpreted as the expected savings from an early contribution. The country which expects a higher potential saving from an early contribution has a stronger incentive to contribute early. Consequently, a targeted investment in cost-reducing technology can change the equilibrium contribution pattern and lead to an equilibrium where one country can free-ride on the early contribution of the other country. Our analysis identified two scenarios where such a potential for freeriding exists and investments in technology affect the countries' timing of contributions. In the first scenario, we considered investments in technology where the current degree of irreversibility would lead to a situation where the countries have a dominant strategy of not contributing before the resolution of the uncertainty; in the second scenario, one country $j$ would contribute already in period $t$, even if no country invests in cost-reducing technology. In both cases, if the investment in technology changes the degree of irreversibility, one country will be more sensitive to this change and will prefer an early contribution. In turn, the other country can reduce its contribution.

Our two-country model can be interpreted as the case of a strategic interaction between two key players (i.e., large regions) that decide over their contribution to climate protection and decide whether or not to implement technology sharing initiatives. This assumption, however, is not particularly restrictive. Assuming quasi-linear preferences, only the countries who potentially have the largest net benefit may choose positive contributions. In a model with $n>2$ countries, the equilibrium probability of contributing will depend on all other 
countries' (expected) valuations, which makes the analysis much more complex and substantially increases the number of cases to be distinguished. The main insights obtained from the two-country model and the resulting trade-off between uncertainty and irreversibility should, however, carry over when considering more than two countries.

Notice that, while our analysis considers investments in technology that lower the irreversibility ratio $c_{t} / c_{t+1}$, it follows directly from our results that different types of investments, with different effects on the irreversibility ratio, can create an opposite situation where investments in technology, which most likely lead to a much lower future contribution cost, shift the equilibrium contributions towards a later date. Our focus on investments in green technologies that have a strong effect on current contribution costs gives consideration to the argument that, by strengthening the other countries' incentives to contribute early, providing such technologies may be beneficial, due to the public good nature of climate protection.

In our model framework, investments in technology affect the timing of contributions and can achieve a discrete change in the countries' equilibrium contributions and, hence, a discrete change in the investing country's payoff (disregarding cost of technology investments). Moreover, in the two scenarios considered, the cost-reducing technology strictly increases the quantity of the public good provided early and therefore the overall amount contributed to climate protection: First, for a given valuation, the optimal early provision level is strictly higher than the optimal late provision level because of the lower marginal contribution cost, and second, early contributions also occur in situations where a country's valuation turns out to be low. (If the valuation turns out to be high, the country can still increase its contribution in the late period.) Both effects cause the total equilibrium quantity of the public good to be higher if the provision is shifted to the early period. From a welfare perspective, such increases in the total quantity provided are desirable, due to the underprovision of the public good in the equilibrium of private contributions. Since the countries' marginal contribution costs within a given period are assumed to be the same and our analysis abstracts from income effects, it does not matter for overall welfare which country contributes in equilibrium. Even if, ex post, a country has over-contributed from an individual perspective, because its early contribution has been higher than what would have been optimal based on the true valuation, such over-contributions from an individual perspective are welfare-increasing, due to the underprovision of the public good. Abstracting from the cost of providing cost-reducing technologies, the shift of the countries' equilibrium contributions towards early contributions will have a positive effect on welfare.

Hindered by the large uncertainties and heterogeneity across countries, international agreements to increase climate protection efforts have been difficult to implement and have remained rather ineffective. Our paper argues that technology sharing mechanisms can, in a 
non-cooperative setting, induce countries to increase their current contributions to climate protection and in this way make technology sharing beneficial for the country that invested in green technology. Promoting technology sharing may, thus, be a promising approach in the fight against climate change.

\section{A Appendix}

\section{A.1 Proof of Lemma 1}

First note that $\pi_{i}\left(x_{t}^{i}\right)$ in (4) is equivalent to

$$
\begin{aligned}
& \int_{0}^{\hat{\theta}} \int_{0}^{\hat{\theta}} \theta^{i} f\left(X_{t}\right) d \Phi_{j}\left(\theta^{j}\right) d \Phi_{i}\left(\theta^{i}\right)+\int_{0}^{\hat{\theta}} \int_{\hat{\theta}}^{\bar{\theta}} \theta^{i} f\left(Q_{t+1}^{j}\left(\theta^{j}\right)\right) d \Phi_{j}\left(\theta^{j}\right) d \Phi_{i}\left(\theta^{i}\right) \\
& +\int_{\hat{\theta}}^{\bar{\theta}} \int_{0}^{\theta^{i}}\left(f\left(Q_{t+1}^{i}\left(\theta^{i}\right)\right)-c_{t+1}\left(Q_{t+1}^{i}\left(\theta^{i}\right)-X_{t}\right)\right) d \Phi_{j}\left(\theta^{j}\right) d \Phi_{i}\left(\theta^{i}\right) \\
& +\int_{\hat{\theta}}^{\bar{\theta}} \int_{\theta^{i}}^{\bar{\theta}} \theta^{i} f\left(Q_{t+1}^{j}\left(\theta^{j}\right)\right) d \Phi_{j}\left(\theta^{j}\right) d \Phi_{i}\left(\theta^{i}\right)-c_{t} x_{t}^{i} .
\end{aligned}
$$

Deriving (15) with respect to $x_{t}^{i}$ yields

$$
\pi_{i}^{\prime}\left(x_{t}^{i}\right)=\int_{0}^{\hat{\theta}} \int_{0}^{\hat{\theta}} \theta^{i} f^{\prime}\left(X_{t}\right) d \Phi_{j}\left(\theta^{j}\right) d \Phi_{i}\left(\theta^{i}\right)+\int_{\hat{\theta}}^{\bar{\theta}} \Phi_{j}\left(\theta^{i}\right) c_{t+1} d \Phi_{i}\left(\theta^{i}\right)-c_{t}
$$

if $0 \leq X_{t}<Q_{t+1}^{i}(\bar{\theta})$ and

$$
\pi_{i}^{\prime}\left(x_{t}^{i}\right)=E\left(\theta^{i}\right) f^{\prime}\left(X_{t}\right)-c_{t}
$$

if $X_{t} \geq Q_{t+1}^{i}(\bar{\theta})$. (This differentiation takes, of course, into account that $\hat{\theta}$ depends on $x_{t}^{i}$; it holds, however, that $\left(\partial \pi_{i} / \partial \hat{\theta}\right)\left(\partial \hat{\theta} / \partial x_{t}^{i}\right)=0$, as in an envelope theorem. Recall that $X_{t}=x_{t}^{A}+x_{t}^{B}$ and $\hat{\theta}=c_{t+1} / f^{\prime}\left(X_{t}\right)$; further, note that $\pi_{i}^{\prime}$ is continuous in $X_{t}$.) Moreover,

$$
\pi_{i}^{\prime \prime}\left(x_{t}^{i}\right)=\left[\begin{array}{ccc}
{\left[\Phi_{j}(\hat{\theta})-\hat{\theta} \Phi_{j}^{\prime}(\hat{\theta})\right] \int_{0}^{\hat{\theta}} \theta^{i} f^{\prime \prime}\left(X_{t}\right) d \Phi_{i}\left(\theta^{i}\right)} & \text { if } & 0 \leq X_{t}<Q_{t+1}(\bar{\theta}) \\
E\left(\theta^{i}\right) f^{\prime \prime}\left(X_{t}\right) & \text { if } \quad X_{t} \geq Q_{t+1}(\bar{\theta})
\end{array}\right.
$$

Here, $\pi_{i}^{\prime \prime}\left(x_{t}^{i}\right)<0$ if $X_{t} \geq Q_{t+1}^{i}(\bar{\theta})$. Moreover, if Assumption 1 holds, then $\pi_{i}^{\prime \prime}\left(x_{t}^{i}\right) \leq 0$ for all $X_{t}$. 
Part (i): Suppose $E\left(\theta^{i}\right) / \bar{\theta} \geq c_{t} / c_{t+1}$. This implies that

$$
\begin{aligned}
\pi_{i}^{\prime}\left(x_{t}^{i} ; X_{t}=Q_{t+1}^{i}(\bar{\theta})\right) & =E\left(\theta^{i}\right) f^{\prime}\left(Q_{t+1}^{i}(\bar{\theta})\right)-c_{t} \\
& =E\left(\theta^{i}\right) f^{\prime}\left(\left(f^{\prime}\right)^{-1}\left(c_{t+1} / \bar{\theta}\right)\right)-c_{t} \geq 0 .
\end{aligned}
$$

Hence, $Q_{t}^{i} \geq Q_{t+1}^{i}(\bar{\theta})$ and $Q_{t}^{i}$ is uniquely determined by

$$
E\left(\theta^{i}\right) f^{\prime}\left(Q_{t}^{i}\right)-c_{t}=0
$$

this yields $Q_{t}^{i}=\left(f^{\prime}\right)^{-1}\left(c_{t} / E\left(\theta^{i}\right)\right) \cdot{ }^{38}$ Since $\left(f^{\prime}\right)^{-1}\left(c_{t} / E\left(\theta^{i}\right)\right) \geq Q_{t+1}^{i}(\bar{\theta})$, there will be no contribution in $t+1$.

Part (ii): $E\left(\theta^{i}\right) / \bar{\theta}<c_{t} / c_{t+1}$. This implies that

$$
\begin{aligned}
\pi_{i}^{\prime}\left(x_{t}^{i} ; X_{t}=Q_{t+1}^{i}(\bar{\theta})\right) & =E\left(\theta^{i}\right) f^{\prime}\left(Q_{t+1}^{i}(\bar{\theta})\right)-c_{t} \\
& =E\left(\theta^{i}\right) f^{\prime}\left(\left(f^{\prime}\right)^{-1}\left(c_{t+1} / \bar{\theta}\right)\right)-c_{t}<0
\end{aligned}
$$

Hence, $0 \leq Q_{t}^{i}<Q_{t+1}^{i}(\bar{\theta})$. (Since $Q_{t+1}^{i}(\bar{\theta})$ is the highest type's preferred contribution level in $t+1, i$ might contribute again in $t+1$.) Moreover, the following relation holds for any $X_{t}<Q_{t+1}^{i}(\bar{\theta})$ :

$$
\begin{aligned}
\pi_{i}^{\prime}\left(x_{t}^{i}\right) & =\int_{0}^{\hat{\theta}} \Phi_{j}(\hat{\theta}) \theta^{i} f^{\prime}\left(X_{t}\right) d \Phi_{i}\left(\theta^{i}\right)+\int_{\hat{\theta}}^{\bar{\theta}} \Phi_{j}\left(\theta^{i}\right) c_{t+1} d \Phi_{i}\left(\theta^{i}\right)-c_{t} \\
& =\int_{0}^{\hat{\theta}} \Phi_{j}(\hat{\theta}) \theta^{i} f^{\prime}\left(X_{t}\right) d \Phi_{i}\left(\theta^{i}\right)+\int_{\hat{\theta}}^{\bar{\theta}} \Phi_{j}\left(\theta^{i}\right) \hat{\theta} f^{\prime}\left(X_{t}\right) d \Phi_{i}\left(\theta^{i}\right)-c_{t} \\
& <\int_{0}^{\hat{\theta}} \theta^{i} f^{\prime}\left(X_{t}\right) d \Phi_{i}\left(\theta^{i}\right)+\int_{\hat{\theta}}^{\bar{\theta}} \theta^{i} f^{\prime}\left(X_{t}\right) d \Phi_{i}\left(\theta^{i}\right)-c_{t} .
\end{aligned}
$$

Hence,

$$
\pi_{i}^{\prime}\left(x_{t}^{i} ; X_{t}=\left(f^{\prime}\right)^{-1}\left(c_{t} / E\left(\theta^{i}\right)\right)\right)<E\left(\theta^{i}\right) f^{\prime}\left(\left(f^{\prime}\right)^{-1}\left(c_{t} / E\left(\theta^{i}\right)\right)\right)-c_{t}=0
$$

and thus $Q_{t}^{i}$ must be strictly smaller than $\left(f^{\prime}\right)^{-1}\left(c_{t} / E\left(\theta^{i}\right)\right)$. Finally,

$$
\pi_{i}^{\prime}\left(x_{t}^{i} ; X_{t}=0\right)=\int_{0}^{\bar{\theta}} \Phi_{j}\left(\theta^{i}\right) c_{t+1} d \Phi_{i}\left(\theta^{i}\right)-c_{t}>0
$$

\footnotetext{
${ }^{38}$ To be precise, if $E\left(\theta^{i}\right) / \bar{\theta}=c_{t} / c_{t+1}$ and $\pi_{i}^{\prime \prime}\left(x_{t}^{i} ; X_{t}\right)=0$ for $X_{t} \in\left(Q_{t+1}^{i}(\bar{\theta})-\delta, Q_{t+1}^{i}(\bar{\theta})\right), \delta>0$, then $i$ is indifferent between all $Q_{t}^{i} \in\left(Q_{t+1}^{i}(\bar{\theta})-\delta, Q_{t+1}^{i}(\bar{\theta})\right)$. For simplicity, we assume that $Q_{t}^{i}=Q_{t+1}^{i}(\bar{\theta})$ in this special case.
} 
or, equivalently, $E\left(\Phi_{j}\left(\theta^{i}\right)\right)>c_{t} / c_{t+1}$ is sufficient for $Q_{t}^{i}>0$, which completes the proof of part (ii)b.

If instead either $(1) \pi_{i}^{\prime}\left(x_{t}^{i} ; X_{t}=0\right)<0$ or $(2) \pi_{i}^{\prime}\left(x_{t}^{i} ; X_{t}=0\right)=0$ and $\pi_{i}^{\prime \prime}\left(x_{t}^{i} ; X_{t}=0\right)<0$, then $Q_{t}^{i}=0$ (part (ii)a). ${ }^{39}$

\section{A.2 Proof of Proposition 2}

Notice that, by assumption, $\gamma(\kappa) \in(0,1)$. If $\gamma$ is strictly decreasing, using the inverse function of $\gamma(\kappa)$, we can define

$$
\kappa_{i}^{p}:=\gamma^{-1}\left(E\left(\Phi_{j}\left(\theta^{i}\right)\right)\right) \text { and } \kappa_{i}^{f}:=\gamma^{-1}\left(E\left(\theta^{i}\right) / \bar{\theta}\right)
$$

First consider case (i), where $\kappa<\kappa_{i}^{f}$ and $\kappa \leq \kappa_{i}^{p}$. This implies that $c_{t}(\kappa) / c_{t+1}(\kappa)>$ $E\left(\theta^{i}\right) / \bar{\theta}$ and $c_{t}(\kappa) / c_{t+1}(\kappa) \geq E\left(\Phi_{j}\left(\theta^{i}\right)\right)$. By Lemma 1(ii)a, country $i$ strictly prefers a provision level of $Q_{t}^{i}=0$ in period $t$.

Now consider case (ii) where $\kappa \geq \kappa_{i}^{f}$, which is equivalent to $c_{t}(\kappa) / c_{t+1}(\kappa) \leq E\left(\theta^{i}\right) / \bar{\theta}$. Using Lemma 1(i), country $i$ prefers a full provision in period $t$.

Finally, in case (iii), as $\gamma$ is strictly decreasing, $\kappa_{i}^{p}<\kappa_{i}^{f}$ is equivalent to $E\left(\Phi_{j}\left(\theta^{i}\right)\right)>$ $E\left(\theta^{i}\right) / \bar{\theta}$. Thus, for $\kappa \in\left(\kappa_{i}^{p}, \kappa_{i}^{f}\right)$, we have $E\left(\Phi_{j}\left(\theta^{i}\right)\right)>c_{t}(\kappa) / c_{t+1}(\kappa)>E\left(\theta^{i}\right) / \bar{\theta}$, and Lemma $1(\mathrm{ii}) \mathrm{b}$ holds. This means that country $i$ prefers a partial provision $Q_{t}^{i} \in$ $\left(0,\left(f^{\prime}\right)^{-1}\left(c_{t} / E\left(\theta^{i}\right)\right)\right)$. Notice that, as shown in Lemma 1 , when $E\left(\Phi_{j}\left(\theta^{i}\right)\right)<E\left(\theta^{i}\right) / \bar{\theta}$ and consequently $\kappa_{i}^{p}>\kappa_{i}^{f}$, then $E\left(\Phi_{j}\left(\theta^{i}\right)\right)$ does not influence the contribution decision, and country $i$ prefers a full provision for all $\kappa \geq \kappa_{i}^{f} \Leftrightarrow c_{t}(\kappa) / c_{t+1}(\kappa) \leq E\left(\theta^{i}\right) / \bar{\theta}$.

\section{A.3 Proof of Proposition 3}

First of all, $\kappa>\min \left\{\kappa_{i}^{p}, \kappa_{i}^{f}\right\}$ implies that $i$ prefers at least a partial provision in $t$ (i.e., $\left.Q_{t}^{i}>0\right)$, while $\kappa<\min \left\{\kappa_{j}^{p}, \kappa_{j}^{f}\right\}$ implies that $Q_{t}^{j}=0 .{ }^{40}$ Since

$$
\max \left\{E\left(\Phi_{j}\left(\theta^{i}\right)\right),\left(E\left(\theta^{i}\right) / \bar{\theta}\right)\right\}=\max \left\{\gamma\left(\kappa_{i}^{p}\right), \gamma\left(\kappa_{i}^{f}\right)\right\}
$$

\footnotetext{
${ }^{39}$ Similar as in part (i), if $\pi_{i}^{\prime}(0)=0$ and Assumption 1 holds with equality for $\theta \in\left[0, \theta^{\prime}\right], \theta^{\prime}>0$, then $\pi_{i}^{\prime}\left(x_{t}^{i} ; X_{t}\right)=0$ for all $X_{t} \in\left[0, Q_{t+1}^{i}\left(\theta^{\prime}\right)\right]$, and $i$ is indifferent between all period $t$ provision levels $Q_{t}^{i} \in\left[0, Q_{t+1}^{i}\left(\theta^{\prime}\right)\right]$. (Note that this does not necessarily imply that $i$ is indifferent between all contributions $x_{t}^{i} \in\left[0, Q_{t+1}\left(\theta^{\prime}\right)\right]$, but $x_{t}^{i}=0$ is at least weakly preferred to all contributions $x_{t}^{i}>0$.) To include this special case in part (ii), we assume that in this case $Q_{t}^{i}=0$.

${ }^{40}$ For simplicity, we omit the cases where $\kappa$ is exactly equal to the thresholds $\kappa_{i}^{f}$ and $\kappa_{i}^{p}$, respectively; the equilibrium contributions in these cases follow directly from the characterization in Proposition 2. The same comment applies to Proposition 4.
} 
and since $\gamma(\kappa)=c_{t}(\kappa) / c_{t+1}(\kappa)$ is strictly decreasing, condition (13) is equivalent to $\min \left\{\kappa_{i}^{p}, \kappa_{i}^{f}\right\}<$ $\min \left\{\kappa_{j}^{p}, \kappa_{j}^{f}\right\}$. Hence, there is a non-empty interval for $\kappa$ where $\left(x_{t}^{i}\right)^{*}>0(i \in\{A, B\}$ is defined such that (13) holds).

\section{A.4 Proof of Proposition 4}

First note that $E\left(\theta^{i}\right)>E\left(\theta^{j}\right)$ is equivalent to $\kappa_{i}^{f}<\kappa_{j}^{f}$. Therefore, (14) requires that $\kappa_{j}^{p}<\kappa_{0}<\min \left\{\kappa_{i}^{p}, \kappa_{i}^{f}\right\}$; at $\kappa_{0}, j$ prefers a partial provision in $t$ while $i$ does not contribute.

Now consider an investment in technology $\kappa \in\left[\kappa_{i}^{f}, \infty\right)$. In this case, $i$ prefers a full provision of the public good in period $t$. Furthermore, $Q_{t}^{i}>Q_{t}^{j}$ because of $E\left(\theta^{i}\right)>E\left(\theta^{j}\right)$; hence, $\left(x_{t}^{i}\right)^{*}>0$ and $\left(x_{t}^{j}\right)^{*}=0$. If $E\left(\theta^{i}\right) / \bar{\theta} \geq E\left(\Phi_{j}\left(\theta^{i}\right)\right)$, then $\kappa_{i}^{f} \leq \kappa_{i}^{p}$, and $i$ prefers a strictly positive period $t$ provision if and only if $\kappa \geq \kappa_{i}^{f}$ (compare Proposition 2). This shows part (i). Otherwise, if $E\left(\theta^{i}\right) / \bar{\theta}<E\left(\Phi_{j}\left(\theta^{i}\right)\right)$, then $\kappa_{i}^{p}<\kappa_{i}^{f}$, and $i$ prefers a strictly positive period $t$ provision for all $\kappa>\kappa_{i}^{p}$. This preferred quantity is increasing in $\kappa$ and converges to $Q_{t}^{i}=\left(f^{\prime}\right)^{-1}\left(c_{t} / E\left(\theta^{i}\right)\right)$ if $\kappa$ approaches $\kappa_{i}^{f}$ (from below). As $\left(f^{\prime}\right)^{-1}\left(c_{t} / E\left(\theta^{i}\right)\right)>\left(f^{\prime}\right)^{-1}\left(c_{t} / E\left(\theta^{j}\right)\right) \geq Q_{t}^{j}$, there exists $\delta>0$ sufficiently small such that for all $\kappa \in\left(\kappa_{i}^{f}-\delta, \infty\right), Q_{t}^{i}>Q_{t}^{j}$ and $\left(x_{t}^{i}\right)^{*}>0$, that is, the investment in technology only needs to bring $i$ 's preferred provision level sufficiently close to a full provision in $t$.

Finally, note that $E\left(\theta^{i}\right)>E\left(\theta^{j}\right)$ is sufficient but not necessary for obtaining the result on the "categorical" change in the equilibrium. If $\kappa_{j}^{p}<\kappa_{0}<\kappa_{i}^{p}<\kappa_{i}^{f}<\kappa_{j}^{f}$, then $E\left(\theta^{i}\right)<$ $E\left(\theta^{j}\right)$, and for $\kappa \in\left[\kappa_{j}^{p}, \kappa_{i}^{f}\right)$, both countries $i$ and $j$ prefer a partial provision of the public good in $t$. Even if $E\left(\theta^{i}\right)<E\left(\theta^{j}\right)$, condition (10) can, depending on the shape of the distribution functions, be positive, which implies that $Q_{t}^{i}>Q_{t}^{j}$ and $\left(x_{t}^{i}\right)^{*}=Q_{t}^{i}>0$.

\section{A.5 Proof of Corollary 1}

Expected equilibrium contributions are $X_{t}^{*}+E\left(X_{t+1}^{*} \mid X_{t}^{*}\right)$ where

$$
\begin{aligned}
E\left(X_{t+1}^{*} \mid X_{t}^{*}\right)= & E_{\theta^{A}, \theta^{B}}\left[\max \left\{\max \left\{Q_{t+1}^{A}\left(\theta^{A}\right), Q_{t+1}^{B}\left(\theta^{B}\right)\right\}-X_{t}^{*}, 0\right\}\right] \\
= & \int_{0}^{\hat{\theta}} \int_{\hat{\theta}}^{\bar{\theta}}\left(Q_{t+1}^{B}\left(\theta^{B}\right)-X_{t}^{*}\right) d \Phi_{B}\left(\theta^{B}\right) d \Phi_{A}\left(\theta^{A}\right) \\
& +\int_{\hat{\theta}}^{\bar{\theta}} \int_{0}^{\theta^{A}}\left(Q_{t+1}^{A}\left(\theta^{A}\right)-X_{t}^{*}\right) d \Phi_{B}\left(\theta^{B}\right) d \Phi_{A}\left(\theta^{A}\right) \\
& +\int_{\hat{\theta}}^{\bar{\theta}} \int_{\theta^{A}}^{\bar{\theta}}\left(Q_{t+1}^{B}\left(\theta^{B}\right)-X_{t}^{*}\right) d \Phi_{B}\left(\theta^{B}\right) d \Phi_{A}\left(\theta^{A}\right) .
\end{aligned}
$$


Hence, with $Q_{t+1}^{A}(\hat{\theta})=Q_{t+1}^{B}(\hat{\theta})=X_{t}^{*}$, we get

$$
\begin{aligned}
\frac{\partial E\left(X_{t+1}^{*} \mid X_{t}^{*}\right)}{\partial X_{t}^{*}} & =-\Phi_{A}(\hat{\theta})\left(1-\Phi_{B}(\hat{\theta})\right)-\left(1-\Phi_{A}(\hat{\theta})\right) \\
& =-\left(1-\Phi_{A}(\hat{\theta}) \Phi_{B}(\hat{\theta})\right) .
\end{aligned}
$$

Intuitively, when $X_{t}^{*}$ is increased, $E\left(X_{t+1}^{*} \mid X_{t}^{*}\right)$ decreases by the same amount, except if both $\theta^{A}$ and $\theta^{B}$ are both lower than the critical valuation $\hat{\theta}$ (in which case there is no contribution in period $t+1$ anyway). Hence, we get

$$
\frac{\partial}{\partial X_{t}^{*}}\left(X_{t}^{*}+E\left(X_{t+1}^{*} \mid X_{t}^{*}\right)\right)=\Phi_{A}(\hat{\theta}) \Phi_{B}(\hat{\theta}) \geq 0
$$

with strict inequality for all $X_{t}^{*}>0$.

\section{A.6 Proof of Corollary 2}

First of all note that

$$
\begin{aligned}
\frac{\partial W}{\partial X_{t}^{*}}= & \Phi_{A}(\hat{\theta}) \Phi_{B}(\hat{\theta})\left[\left(E\left(\theta^{A} \mid \theta^{A} \leq \hat{\theta}\right)+E\left(\theta^{A} \mid \theta^{A} \leq \hat{\theta}\right)\right) f^{\prime}\left(X_{t}^{*}\right)-c_{t}\right] \\
& +\left(1-\Phi_{A}(\hat{\theta}) \Phi_{B}(\hat{\theta})\right)\left(c_{t+1}-c_{t}\right) .
\end{aligned}
$$

(Since $\partial W / \partial X_{t}^{*}=\partial \pi_{i} / \partial X_{t}^{*}+\partial \pi_{j} / \partial X_{t}^{*}$, (16) is obtained, for instance, by adding (6) and $j$ 's marginal payoff in case $i$ 's period $t$ contribution increases.) Intuitively, if both countries' valuations turn out to be lower than the critical valuation (the first term in (16)), then the welfare effect follows the standard cost-benefit considerations where benefits are evaluated with the sum of expected valuations conditional on being smaller than the critical valuation $\hat{\theta}$. If at least one country's valuation is higher than the critical valuation, there is a cost saving $c_{t+1}-c_{t}$ in case the early contribution is increased. (Compared to a single country's marginal payoff as in (6), the free-riding effect disappears.)

Case (i): $X_{t}^{*}=0$. In this case, $\hat{\theta}=0$ and $\partial W / \partial X_{t}^{*}=c_{t+1}-c_{t}>0$. (As in the one-country scenario analyzed in Section 4 , there should always be a strictly positive early contribution from a welfare perspective.)

Case (ii): $X_{t}^{*}>0$. Suppose without loss of generality that $\left(x_{t}^{i}\right)^{*}>0$. Hence, $\partial \pi_{i} / \partial\left(x_{t}^{i}\right)^{*}=0$ 
and

$$
\begin{aligned}
\frac{\partial W}{\partial X_{t}^{*}} & =\frac{\partial \pi_{i}}{\partial\left(x_{t}^{i}\right)^{*}}+\frac{\partial \pi_{j}}{\partial\left(x_{t}^{i}\right)^{*}} \\
& =0+\int_{0}^{\hat{\theta}} \int_{0}^{\hat{\theta}} \theta^{j} f^{\prime}\left(X_{t}^{*}\right) d \Phi_{j}\left(\theta^{j}\right) d \Phi_{i}\left(\theta^{i}\right)+\int_{0}^{\bar{\theta}} \int_{\max \left\{\theta^{i}, \hat{\theta}\right\}}^{\bar{\theta}} c_{t+1} d \Phi_{j}\left(\theta^{j}\right) d \Phi_{i}\left(\theta^{i}\right) \\
& >0 .
\end{aligned}
$$

While the country $i$ that increases $X_{t}^{*}$ only takes into account its own marginal payoff, the other country is $j$ is made strictly better off.

\section{A.7 Effect of technology on positive optimal contribution levels}

While the main analysis of the effect of investments in cost-reducing technology $\kappa$ has focused on "categorical changes" of a country's preferred provision level in $t$, this appendix considers the effect of a marginal change in $\kappa$ on an initially positive contribution level. Obviously, if the irreversibility ratio $c_{t} / c_{t+1}$ is close to one and the countries do not want to contribute in $t$, a marginal change in $\kappa$ has no effect on the preferred period $t$ provision. On the other hand, if there is a high degree of irreversibility $\left(c_{t} / c_{t+1}\right.$ is low $)$ and the countries prefer a full provision of the public good in $t$, a marginal investment in technology simply marginally increases this preferred amount, since there still will be no contributions in period $t+1$. The only interesting case to consider is, hence, a situation where countries prefer a partial provision of the public good in $t$ and contribute in $t+1$ with positive probability.

Remark 1 Suppose that $Q_{t}^{i} \in\left(0,\left(f^{\prime}\right)^{-1}\left(c_{t} / E\left(\theta^{i}\right)\right)\right)$. Then, $Q_{t}^{i}$ is strictly increasing in $\kappa$ if and only if $\left|\frac{\partial c_{t}}{\partial \kappa}\right|>D\left|\frac{\partial c_{t+1}}{\partial \kappa}\right|$ where

$$
D:=\int_{0}^{\hat{\theta}} \Phi_{j}^{\prime}(\hat{\theta}) \theta^{i} d \Phi_{i}\left(\theta^{i}\right)+\int_{\hat{\theta}}^{\bar{\theta}} \Phi_{j}\left(\theta^{i}\right) d \Phi_{i}\left(\theta^{i}\right)<1 .
$$

Proof. $Q_{t}^{i}$ is determined by the condition

$$
\int_{0}^{\hat{\theta}} \Phi_{j}(\hat{\theta}) \theta^{i} f^{\prime}\left(Q_{t}^{i}\right) d \Phi_{i}\left(\theta^{i}\right)+\int_{\hat{\theta}}^{\bar{\theta}} \Phi_{j}\left(\theta^{i}\right) c_{t+1} d \Phi_{i}\left(\theta^{i}\right)-c_{t}=0,
$$

where $\hat{\theta}=c_{t+1} / f^{\prime}\left(Q_{t}^{i}\right)$. Total differentiation yields

$$
\frac{\partial Q_{t}^{i}}{\partial \kappa}=-\frac{\left(\int_{0}^{\hat{\theta}} \Phi_{j}^{\prime}(\hat{\theta}) \theta^{i} d \Phi_{i}\left(\theta^{i}\right)+\int_{\hat{\theta}}^{\bar{\theta}} \Phi_{j}\left(\theta^{i}\right) d \Phi_{i}\left(\theta^{i}\right)\right) \frac{\partial c_{t+1}}{\partial \kappa}-\frac{\partial c_{t}}{\partial \kappa}}{\pi_{i}^{\prime \prime}\left(Q_{t}^{i}\right)}
$$


hence, $\partial Q_{t}^{i} / \partial \kappa>0$ if and only if $D\left(\partial c_{t+1} / \partial \kappa\right)-\partial c_{t} / \partial \kappa>0$ or $\left|\partial c_{t} / \partial \kappa\right|>D\left|\partial c_{t+1} / \partial \kappa\right|$. It remains to show that $D<1$. By Assumption $1, \Phi_{j}^{\prime}(\hat{\theta}) \leq \Phi_{j}(\hat{\theta}) / \hat{\theta}$, and, hence,

$$
\begin{aligned}
D & \leq \int_{0}^{\hat{\theta}} \frac{\Phi_{j}(\hat{\theta})}{\hat{\theta}} \theta^{i} d \Phi_{i}\left(\theta^{i}\right)+\int_{\hat{\theta}}^{\bar{\theta}} \Phi_{j}\left(\theta^{i}\right) d \Phi_{i}\left(\theta^{i}\right) \\
& <\int_{0}^{\hat{\theta}} \Phi_{j}(\hat{\theta}) d \Phi_{i}\left(\theta^{i}\right)+\int_{\hat{\theta}}^{\bar{\theta}} \Phi_{j}\left(\theta^{i}\right) d \Phi_{i}\left(\theta^{i}\right)<1 .
\end{aligned}
$$

In line with the analysis of "categorical changes", as long as a marginal change in $\kappa$ does not change $c_{t+1}$ much stronger than $c_{t}$, a marginal investment in cost-reducing technology increases country $i$ 's preferred provision level in period $t$, in a situation where $i$ prefers a partial provision in $t$ and the probability of a contribution in $t+1$ is strictly positive.

With regard to this late contribution in period $t+1$, the effect of a marginal change in $\kappa$ on the expected contributions in $t+1$ is ambiguous. Intuitively, a change in $\kappa$ reduces $c_{t+1}$, which, keeping total contributions in $t$ unchanged, increases a country's expected contribution in $t+1$. But the change in $\kappa$ also reduces $c_{t}$, which, as shown, typically increases $Q_{t}^{A}$ and $Q_{t}^{B}$ and, hence, increases total contributions in $t$; higher early contributions, however, reduce a country's expected contribution in $t+1$. Mathematically,

$$
E\left(x_{t+1}^{*}\right)=\int_{\hat{\theta}}^{\bar{\theta}} \Phi_{j}\left(\theta^{i}\right)\left(Q_{t+1}^{i}\left(\theta^{i}\right)-X_{t}\right) d \Phi_{i}\left(\theta^{i}\right)
$$

and, hence,

$$
\begin{aligned}
\frac{\partial E\left(\left(x_{t+1}^{i}\right)^{*}\right)}{\partial \kappa} & =\int_{\hat{\theta}}^{\bar{\theta}} \Phi_{j}\left(\theta^{i}\right)\left(\frac{\partial Q_{t+1}^{i}\left(\theta^{i}\right)}{\partial \kappa}-\frac{\partial X_{t}}{\partial \kappa}\right) d \Phi_{i}\left(\theta^{i}\right) \\
& =\int_{\hat{\theta}}^{\bar{\theta}} \Phi_{j}\left(\theta^{i}\right)\left(\frac{1}{\theta^{i} f^{\prime \prime}\left(Q_{t+1}^{i}\left(\theta^{i}\right)\right)} \frac{\partial c_{t+1}}{\partial \kappa}-\frac{\partial X_{t}}{\partial \kappa}\right) d \Phi_{i}\left(\theta^{i}\right)
\end{aligned}
$$

where the first term in the integrand is positive (the direct effect on $Q_{t+1}^{i}$ ) and the second term is negative (the indirect effect through $X_{t}$ ); overall, whether a country's expected contribution in $t+1$ increases or decreases depends not only on the shape of $f$ but also on how both countries' preferred provision levels in $t$ change. 


\section{References}

[1] A. R. Admati And M. Perry. Joint projects without commitment. Review of Economic Studies 58(2), 259-276 (1991).

[2] J. E. Aldy, P. R. Orszag, and J. E. Stiglitz. Climate change: An agenda for global collective action. Working Paper, prepared for the conference on The Timing of Climate Change Policies, Pew Center on Global Climate Change, Washington, D.C. (2001).

[3] M. Allen, D. Frame, C. Huntingford, C. Jones, J. Lowe, M. Malte, and N. Meinshausen. Warming caused by cumulative carbon emissions towards the trillionth tonne. Nature 458, 1163-1166 (2009).

[4] K. J. Arrow And A. C. Fisher. Environmental preservation, uncertainty, and irreversibility. The Quarterly Journal of Economics 88(2), 312-319 (1974).

[5] S. BARRETT. "Environment and statecraft: the strategy of environmental treaty making". Oxford University Press, New York (2003).

[6] S. Barrett. "Why cooperate? The incentive to supply local public goods." Oxford University Press, New York (2007).

[7] J. Beccherle and J. Tirole. Regional initiatives and the cost of delaying binding climate change agreements. Journal of Public Economics 95(11-12), 1339-1348 (2011).

[8] T. Bergstrom, L. Blume, and H. Varian. On the private provision of public goods. Journal of Public Economics 29(1), 25-49 (1986).

[9] V. Boucher and Y. Bramoullé. Providing global public goods under uncertainty. Journal of Public Economics 94(9-10), 591-603 (2010).

[10] Y. Bramoullé And N. Treich. Can uncertainty alleviate the commons problem? Journal of the European Economic Association 7(5), 1042-1067 (2009).

[11] W. Buchiolz, A. Haupt, and W. Peters. International environmental agreements and strategic voting. Scandinavian Journal of Economics 107(1), 175-195 (2005).

[12] W. Buchholz and K. Konrad. Global environmental problems and the strategic choice of technology. Journal of Economics 60(3), 299-321 (1994).

[13] W. Buchholz and K. A. Konrad. Strategic transfers and private provision of public goods. Journal of Public Economics 57(3), 489-505 (1995). 
[14] O. Compte and P. Jehiel. Voluntary contributions to a joint project with asymmetric agents. Journal of Economic Theory 112(2), 334-342 (2003).

[15] J. M. Conrad. Quasi-option value and the expected value of information. The Quarterly Journal of Economics 94(4), 813-820 (1980).

[16] R. Cornes And T. SAndler. The simple analytics of pure public good provision. Economica 52(205), 103-116 (1985).

[17] S. Dietz and N. Stern. Why economic analysis supports strong action on climate change: A response to the stern review's critics. Review of Environmental Economics and Policy 2(1), 94-113 (2008).

[18] L. Epstein. Decision making and the temporal resolution of uncertainty. International economic review 21(2), 269-283 (1980).

[19] C. Fershtman and S. Nitzan. Dynamic voluntary provision of public goods. European Economic Review 35(5), 1057-1067 (1991).

[20] A. C. Fisher. Investment under uncertainty and option value in environmental economics. Resource and Energy Economics 22(3), 197-204 (2000).

[21] A. Glazer And S. Proost. Informational benefits of international treaties. Environmental and Resource Economics 53(2), 185-202 (2012).

[22] C. Gollier, B. Jullien, And N. Treich. Scientific progress and irreversibility: an economic interpretation of the 'precautionary principle'. Journal of Public Economics 75(2), 229-253 (2000).

[23] R. Golombek and M. Hoel. Climate policy under technology spillovers. Environmental and Resource Economics 31(2), 201-227 (2005).

[24] R. Golombek And M. Hoel. International cooperation on climate-friendly technologies. Environmental and Resource Economics 49(4), 473-490 (2011).

[25] M. Gradstein. Time dynamics and incomplete information in the private provision of public goods. Journal of Political Economy 100(3), 581-597 (1992).

[26] B. Harstad. The dynamics of climate agreements. CESifo Working Paper No. 2962 (2010).

[27] C. Henry. Investment decisions under uncertainty: The irreversibility effect. American Economic Review 64(6), 1006-1012 (1974).

[28] M. Hoel. Global environmental problems: The effects of unilateral actions taken by one country. Journal of Environmental Economics and Management 20(1), 55-70 (1991). 
[29] IPCC. "Climate Change 2007: Synthesis Report." Intergovernmental Panel on Climate Change, Geneva (2007).

[30] S. Jamet and J. Corfee-Morlot. Assessing the impacts of climate change: A literature review. OECD Economics Department Working Paper No. 691 (2009).

[31] S. Kessing. Strategic complementarity in the dynamic private provision of a discrete public good. Journal of Public Economic Theory 9(4), 699-710 (2007).

[32] C. Kolstad. Fundamental irreversibilities in stock externalities. Journal of Public Economics 60(2), 221-233 (1996).

[33] C. Kolstad and A. Ulph. Learning and international environmental agreements. Climatic Change 89(1), 125-141 (2008).

[34] K. A. Konrad and M. Thum. Climate policy negotiations with incomplete information. Economica (forthcoming).

[35] B. Lockwood and J. P. Thomas. Gradualism and irreversibility. Review of Economic Studies 69(2), 339-356 (2002).

[36] L. M. Marx and S. A. Matthews. Dynamic voluntary contribution to a public project. Review of Economic Studies 67(2), 327-358 (2000).

[37] R. McDonald and D. Siegel. The value of waiting to invest. The Quarterly Journal of Economics 101(4), 707-727 (1986).

[38] R. Mendelsohn. Is the stern review an economic analysis. Review of Environmental Economics and Policy 2(1), 45-60 (2008).

[39] F. Morath. Strategic information acquisition and the mitigation of global warming. Journal of Environmental Economics and Management 59(2), 206-217 (2010).

[40] B. Moselle, J. Padilla, and R. Schmalensee. "Harnessing Renewable Energy in Electric Power Systems: Theory, Practice, Policy". Earthscan LLC (2010).

[41] S. Na AND H. Shin. International environmental agreements under uncertainty. Oxford Economic Papers 50(2), 173-185 (1998).

[42] R. S. Pindyck. Irreversibility, uncertainty, and investment. Journal of Economic Literature 29(3), 1110-1148 (1991).

[43] R. S. Pindyck. Optimal timing problems in environmental economics. Journal of Economic Dynamics and Control 26(9-10), 1677-1697 (2002).

[44] R. C. Schmidt and R. Strausz. The timing of climate agreements under multiple externalities. SFB/TR 15 Discussion Paper No. 366 (2011). 
[45] S. A. SнAн. A noncooperative quantity-rationing theory of transboundary pollution. Journal of Public Economic Theory 12(3), 437-470 (2010).

[46] N. Stern. "Stern review on the economics of climate change". Cambridge Universtiy Press (2007).

[47] A. Ulph and D. Ulph. Global warming, irreversibility and learning. Economic Journal 107(442), 636-650 (1997).

[48] UNEP. "Global trends in renewable energy investment 2011". United Nations Environment Programme and Bloomberg New Energy Finance (2011).

[49] UNFCCC. United nations framework convention on climate change. (1992).

[50] H. R. VARIAn. Sequential contributions to public goods. Journal of Public Economics 53(2), 165-186 (1994). 